\title{
Task 5.9 - Use of Coal Ash in Recycled Plastics and Composite Materials
}

\author{
Topical Report \\ July 1995 \\ By \\ David J. Hassett \\ Bruce A. Dockter . \\ Kurt E. Eylands \\ Debra F. Pflughoeft-Hassett
}

Work Performed Under Contract No.: DE-FC21-93MC30097

For

U.S. Department of Energy

Office of Fossil Energy

Federal Energy Technology Center

Morgantown Site

P.O. Box 880

Morgantown, West Virginia 26507-0880

By

Energy \& Environmental Research Center

University of North Dakota

P. O. Box 9018

Grand Forks, North Dakota 58202-9018

DABTABUTION OF THS DOCUMENT is UN UTRE 


\section{Disclaimer}

This report was prepared as an account of work sponsored by an agency of the United States Government. Neither the United States Government nor any agency thereof, nor any of their employees, makes any warranty, express or implied, or assumes any legal liability or responsibility for the accuracy, completeness, or usefulness of any information, apparatus, product, or process disclosed, or represents that its use would not infringe privately owned rights. Reference herein to any specific commercial product, process, or service by trade name, trademark, manufacturer, or otherwise does not necessarily constitute or imply its endorsement, recommendation, or favoring by the United States Government or any agency thereof. The views and opinions of authors expressed herein do not necessarily state or reflect those of the United States Government or any agency thereof. 


\section{DISCLAIMER}

Portions of this document may be illegible electronic image products. Images are produced from the best available original document. 


\section{DISCLAIMER}

This report was prepared as an account of work sponsored by an agency of the United States Government. Neither the United States Government, nor any agency thereof, nor any of their employees makes any warranty, express or implied, or assumes any legal liability or responsibility for the accuracy, completeness, or usefulness of any information, apparatus, product, or process disclosed or represents that its use would not infringe privately owned rights. Reference herein to any specific commercial product, process, or service by trade name, trademark, manufacturer, or otherwise does not necessarily constitute or imply its endorsement, recommendation, or favoring by the United States Government or any agency thereof. The views and opinions of authors expressed herein do not necessarily state or reflect those of the United States Government or any agency thereof.

\section{ACKNOWLEDGMENT}

This final topical report was prepared with the support of the U.S. Department of Energy (DOE) Morgantown Energy Technology Center, Cooperative Agreement No. DE-FC2193MC30097. However, any opinions, findings, conclusions, or recommendations expressed herein are those of the author(s) and do not necessarily reflect the views of the DOE.

\section{EERC DISCLAIMER}

LEGAL NOTICE This research report was prepared by the Energy \& Environmental Research Center (EERC), an agency of the University of North Dakota, as an account of work sponsored by the U.S. Department of Energy. Because of the research nature of the work performed, neither the EERC nor any of its employees makes any warranty, express or implied, or assumes any legal liability or responsibility for the accuracy, completeness, or usefulness of any information, apparatus, product, or process disclosed, or represents that its use would not infringe privately owned rights. Reference herein to any specific commercial product, process, or service by trade, trademark, manufacturer, or otherwise does not necessarily constitute or imply its endorsement or recommendation by the EERC. 


\section{TABLE OF CONTENTS}

LIST OF FIGURES $\ldots \ldots \ldots \ldots \ldots \ldots \ldots \ldots \ldots \ldots \ldots \ldots \ldots \ldots \ldots \ldots \ldots$

LIST OF TABLES $\ldots \ldots \ldots \ldots \ldots \ldots \ldots \ldots \ldots \ldots \ldots \ldots$

$1.0 \quad$ INTRODUCTION $\ldots \ldots \ldots \ldots \ldots \ldots \ldots \ldots \ldots \ldots \ldots \ldots \ldots \ldots \ldots \ldots \ldots$

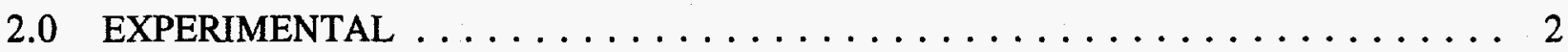

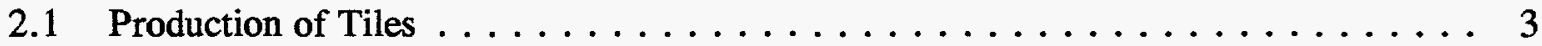

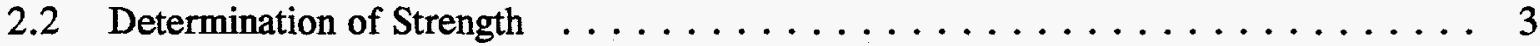

2.3 Determination of Ash Content $\ldots \ldots \ldots \ldots \ldots \ldots \ldots \ldots \ldots \ldots$

3.0 RESULTS AND DISCUSSION $\ldots \ldots \ldots \ldots \ldots \ldots \ldots \ldots \ldots \ldots \ldots$

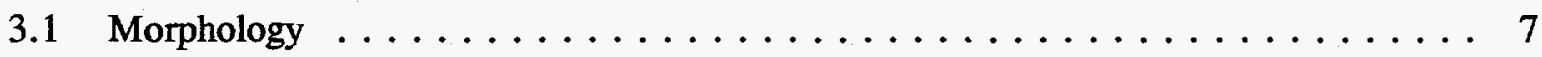

3.1 .1 Raw Materials .................... 7

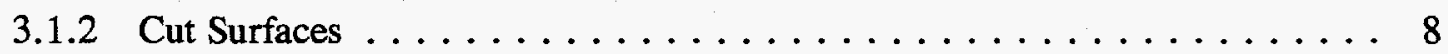

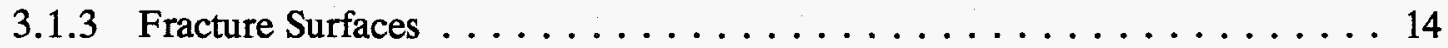

3.2 Physical Properties of the Tiles $\ldots \ldots \ldots \ldots \ldots \ldots \ldots \ldots \ldots \ldots \ldots$

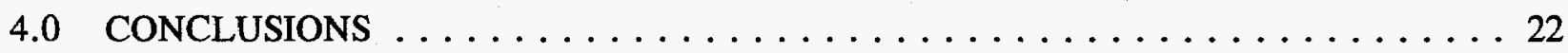




\section{LIST OF FIGURES}

1 CG cenospheres $\ldots \ldots \ldots \ldots \ldots \ldots \ldots \ldots \ldots \ldots \ldots \ldots \ldots$

2 SG cenospheres $\ldots \ldots \ldots \ldots \ldots \ldots \ldots \ldots \ldots \ldots \ldots \ldots \ldots \ldots$

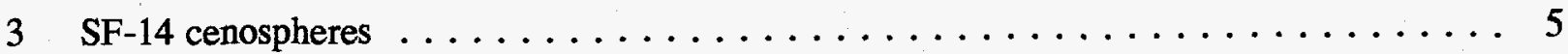

$4 \quad$ Ash $\ldots \ldots \ldots \ldots \ldots \ldots \ldots \ldots \ldots \ldots \ldots \ldots \ldots \ldots$

$5 \# 1$ Tile $006 \ldots \ldots \ldots \ldots \ldots \ldots \ldots \ldots \ldots \ldots \ldots \ldots \ldots \ldots$

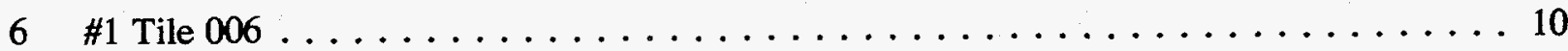

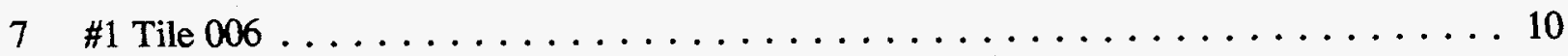

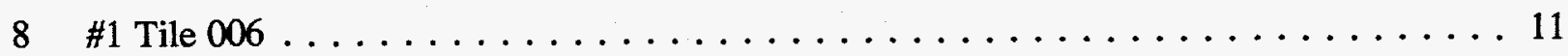

9 Tile 008 CG cenospheres $\ldots \ldots \ldots \ldots \ldots \ldots \ldots \ldots \ldots \ldots \ldots \ldots$

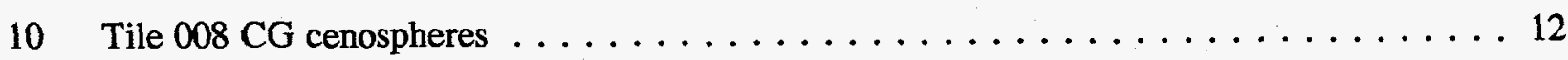

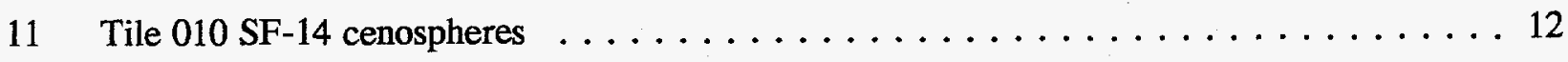

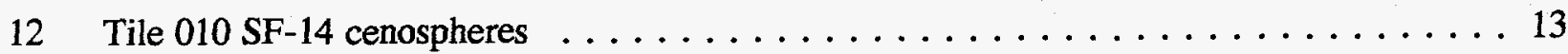

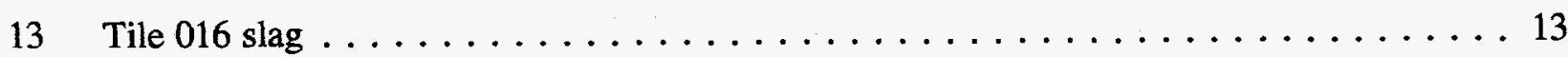

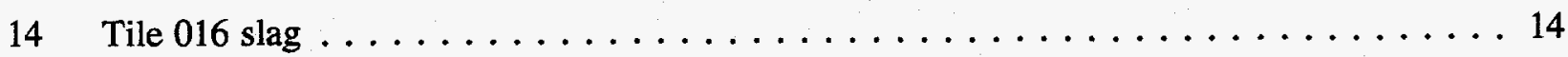

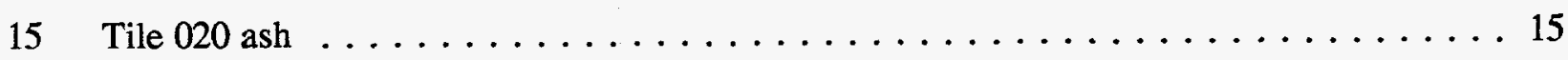

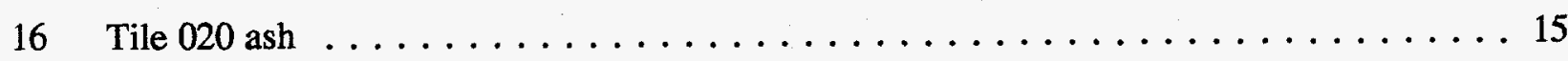

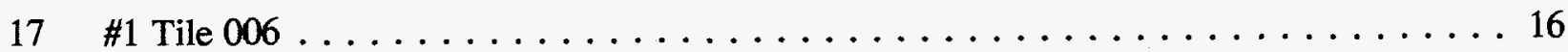

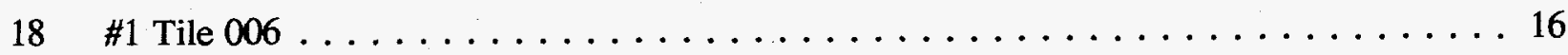

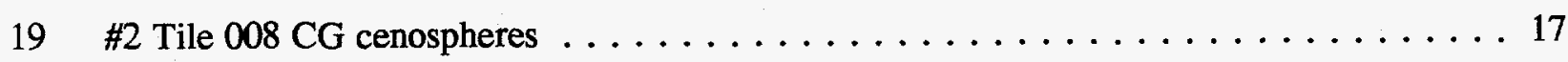

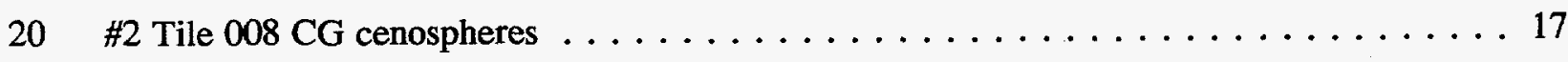

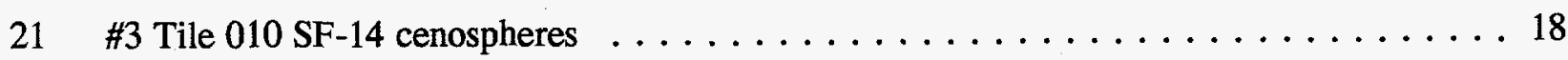

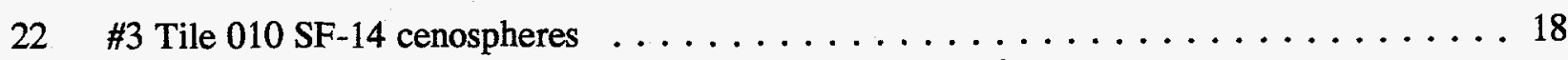

Continued ... 


\section{LIST OF FIGURES (continued)}

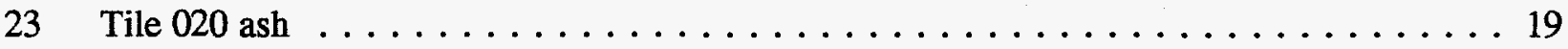

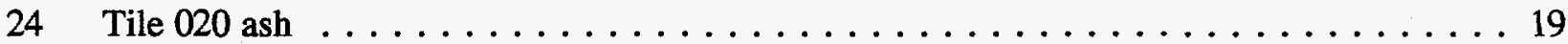

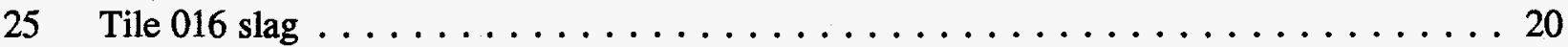

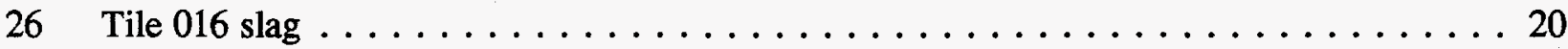

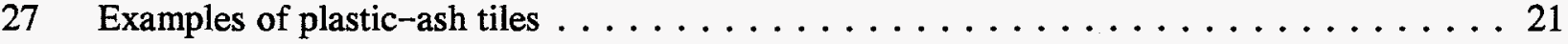

\section{LIST OF TABLES}

1 Plastic-Ash Tile Composition and Properties $\ldots \ldots \ldots \ldots \ldots \ldots \ldots \ldots$

2 Plastic-Ash Tile Selected Physical Properties $\ldots \ldots \ldots \ldots \ldots \ldots \ldots \ldots \ldots$ 


\section{TASK 5.9 - USE OF COAL ASH IN RECYCLED PLASTICS AND COMPOSITE MATERIALS}

\subsection{INTRODUCTION}

The goal of this research project by the Energy \& Environmental Research Center (EERC) was to determine the potential for coal ash to serve as a "functional filler" in plastics and other composite materials, with special emphasis on recycled plastics. The term functional filler is intended to indicate that the material added to the plastic does more than take up space and extend the use of the polymer. Determining the functional filler potential of ash was not the only intent of this project, since another prime objective was to find a use for materials currently considered waste. The term functional filler also opened a door to the use of cenospheres, which are currently marketed and for which there is sufficient market demand that they do not fit the category of a waste even though they are a product of coal combustion. Cenospheres, hollow spherical ash particles, were selected because of their unique properties. Although they currently have commercial applications, the unique nature of these materials make them an excellent candidate for use as a functional filler in composites. The ability to produce a commercially viable product from waste streams and a recycled material is a positive step toward reducing solid waste. The first task, since there are numerous types of coal ash, was to select suitable ash types for use in this project. Three basic types of material were selected: fly ash, a bottom ash, and a unique form of coal ash known as cenospheres.

The initial intent was to use recycled plastic as the binding material. Various attempts were made at melting and forming composites using polyethylene and polyvinyl chloride because these two waste materials could be melted under laboratory conditions. It soon became apparent that without the proper equipment for melting, mixing, molding, extruding, and forming this was not a suitable approach. The approach was shifted to the use of commercially, available polymeric materials that could be used as a starting point in our formulations. Although the materials were not exactly like what would be used commercially, they allowed the demonstration and testing of various combinations. The exploration of all possible recycle plastic streams was beyond the scope of this project. Two polymeric materials exhibiting different properties were selected for the demonstration: 1) polyester, which is polymerized through a free radical mechanism using 2-butanone peroxide and 2) acrylic, which is polymerized through a cross-linking of an already partially polymerized product. These are representative of many recycle streams and components and allowed the formation of composite materials for examining basic properties and studying how ash and plastic interacted as composites. Since the formulation of the selected materials are proprietary, the exact composition of individual components was not known. In practice, the variety of acrylic and polyester in recycle streams would be relatively large. The likely source of polyester would be from plastic carbonated beverage containers. Polyester is used in this application because of its ability to retain carbonation. Most common polymers are permeable to gases, especially carbon dioxide under pressure.

Polyesters can be prepared with high strength-tensile strength as high as 25,000 psi can be achieved. Additionally, polyesters are relatively scratch-resistant. Acrylic polymer recycle material would likely come from industrial sources where acrylics are used in the fabrication of various products. The term acrylic encompasses a large variety of polymers dominated by poly(methyl methacrylate), better known as plexiglas. Additionally, poly(methyl methacrylate) composite dental fillings are prepared from a polymer-monomer dough with a ceramic filler (not unlike coal ash), thus demonstrating the high strength that can be achieved with this material. The polymer produced in this manner is what is described as atactic, which means that there is no regular structure in the 
polymer chain, it has a high molecular weight-as high as $10^{6}$, and it is amorphous. Acrylic polymers have high strength and relatively high flow resistance but scratch easily. Tensile strengths as high as $8000-10,000$ psi and shear strengths from 7500 to 11,000 psi can be achieved, although these are lower than what is expected from polyester described above. Key areas such as polymer-ash interactions, adhesion, and basic composite properties were investigated.

\subsection{EXPERIMENTAL}

The objective of this project was to investigate the use of coal combustion by-products (CCBs) in plastic formulations. The intent was to produce a new type of material combining the properties of CCBs and plastics. CCBs were used as fillers, but more importantly, they were used and selected on their potential to alter the basic properties of the plastic and formulate a new material using CCBs as functional fillers.

CCBs are numerous, and for this project, three materials were selected on the basis of using their various chemical, physical, and mineralogical properties to advantage in plastic formulations:

- A slag was obtained from a lignite-fired wet-bottom cyclone boiler plant. The reason for choosing this source of slag was twofold. First was the availability of significant amounts, if needed, for larger-scale utilization. The wet-bottom boiler slag is sluiced into holding ponds located on or near plant sites. The second reason for selection was the consistency of the material produced over years of on-line activity at the power plant. Both reasons are important for ensuring a reliable source of functional filler that meets the necessary quality assurances.

- A fly ash, from a pc-fired plant also firing lignite, was chosen to add additional "fines" to the mixture. An appropriate blend of particle sizes enhances the stability of a plastic tile composite. A mixture with little or no gradation of functional filler will tend to be more brittle when fractured. This particular fly ash was chosen because it is a less salable source of pulverized coal combustion fly ash than currently marketed in the region. Thus it would more likely be disposed of than utilized.

- Cenospheres were selected because they have, perhaps, the greatest potential for modifying plastics and forming a material with unique properties. Cenospheres are hollow, spherical, usually amorphous units ranging in size from 2 to 300 micrometers in diameter. Cenospheres can be complex in nature, with a hollow sphere containing smaller spheres, which in turn also contain very small cenospheres. This makes the material extremely light, with a nominal bulk density of 0.4 grams per cubic centimeter and the capability of forming a composite with a bulk density lighter than water. Additionally, cenospheres can retain the mineralogical and chemical properties of the parent fly ash, thus being pozzolanic in nature. Cenospheres as well as other types of reactive CCBs have the potential to produce a material with surface properties being a mix between the plastic binder and the filler material.

Cenospheres were obtained from the PQ Corporation of Chattanooga TN. These materials called extendospheres came in three grades. SG extendospheres were 10-350 microns with a mean particle diameter of 100 microns; CG extendospheres were 10-200 microns with a mean particle 
diameter of 90 microns; and SF-14 extendospheres were 10-100 microns with a mean particle diameter of 55 microns. All were free-flowing powders light grey in color, with the SF-14 material slightly lighter in color. Figures 1 through 3 show scanning electron micrograph photos of these materials. It can be seen that the SF-14 material stands out as being of a more uniform and smaller size than either the CG or SG cenospheres.

\subsection{Production of Tiles}

Molds for tile production were prepared from a commercially available room temperature vulcanizing (RTV) liquid rubber produced by Polytek Development Corporation, Lebanon, NJ. This two-part material was mixed according to manufacturer's instructions and poured around a commercially available ceramic tile placed on the bottom of a shallow pan. After curing, the material was removed from the pan, and the tile was removed, leaving an impression of the tile into which composite formulations could be poured. Composite formulations were prepared from cold mounting compounds purchased from Buehler, Lake Bluff, IL. A two-part acrylic and a polyester resin/catalyst system were used in the formulation of tiles. The polymer was mixed according to manufacturer's instructions. While it was still relatively free-flowing, immediately after mixing of the two-part system or addition of catalyst ash, it was blended by volume with minimal incorporation of air. For each of the combinations produced, the volume of ash to unit volume of polymer was determined by trial and error. The formulation of choice yielded material that was pourable and would flow out to a uniform level in the mold before hardening. The mixed composite of ash and polymer was poured into the mold and placed in a vacuum desiccator for vacuum degassing to remove any air incorporated during mixing. After vacuum degassing, the mold was placed on a flat surface to cure. It was determined that mold release compound was unnecessary with the materials being used. After curing, the tile was removed from the mold and marked for identification. If sufficient material was left over from the casting, this was used to determine ash-to-plastic ratio. If insufficient material was available a portion of the tile was used. The listing of tiles fabricated along with available data are listed in Table 1.

\subsection{Determination of Strength}

The flexural strength was determined using American Standards for Testing and Materials (ASTM) standard test method C293, Flexural Strength of Concrete (using simple beam with centerpoint loading). The 3-inch-square tiles were arranged such that the span length between the two support blocks was $2 \frac{1}{2}$ inches. The width of each specimen was 3 inches, and the average depth was dependent on the thickness of the tiles tested. In addition to strength testing, the plastic tiles were also evaluated for unit weight and bulk specific gravity. The results for all physical testing are contained in Table 2.

\subsection{Determination of Ash Content}

A portion of the material used for tile preparation or a portion of the tile was placed into an ignited and tared crucible. The weight was recorded before and after heating at $750^{\circ} \mathrm{C}$ to constant weight. The weight lost during ignition as well as the weight of ash remaining was used to calculate the mass of ash and plastic. 


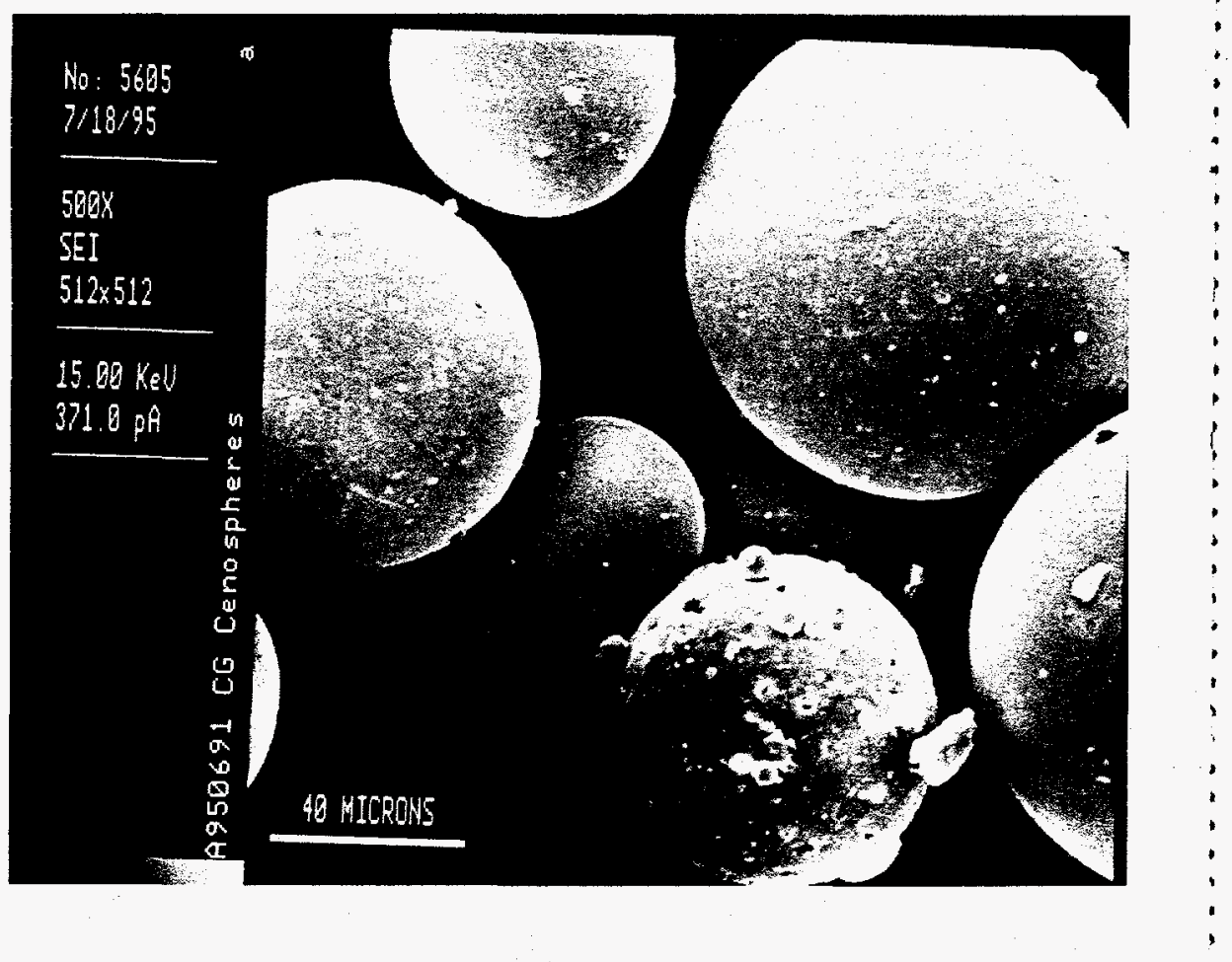

Figure 1. CG cenospheres

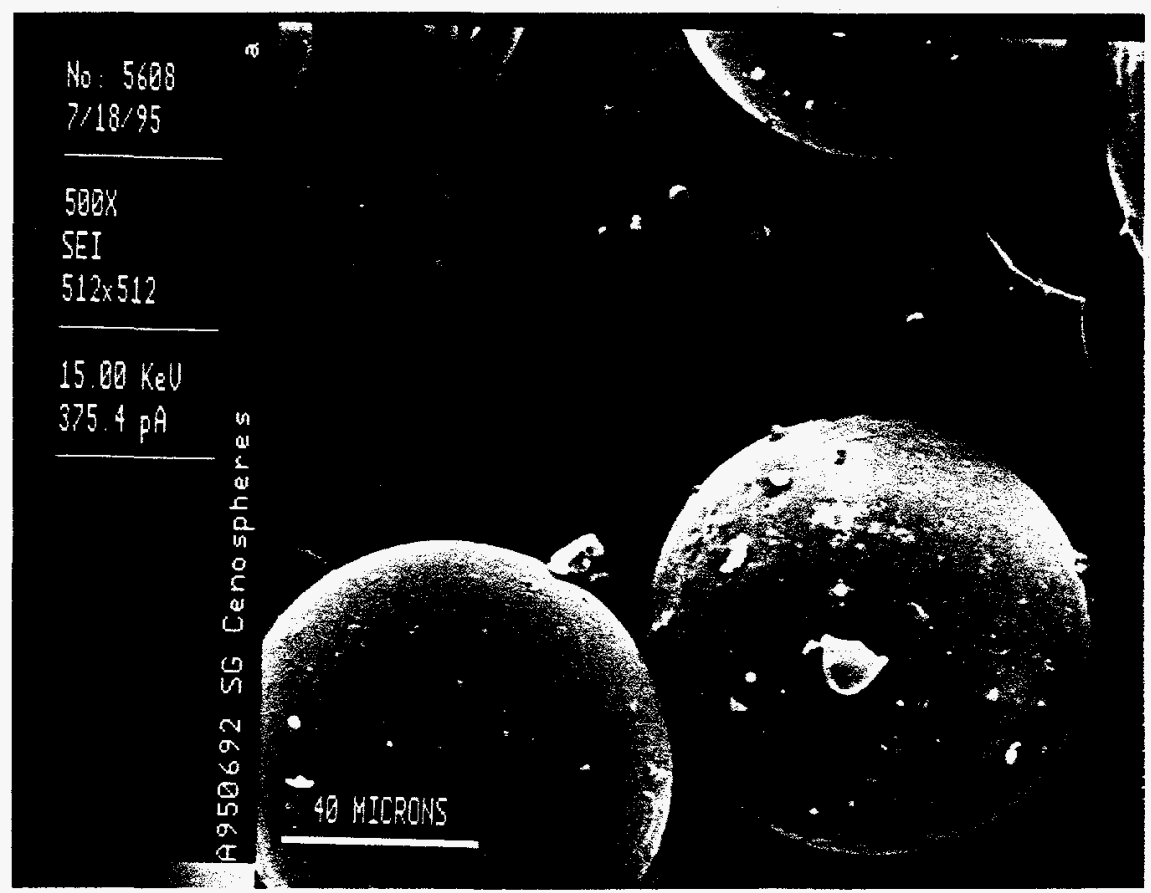

Figure 2. SG cenospheres. 


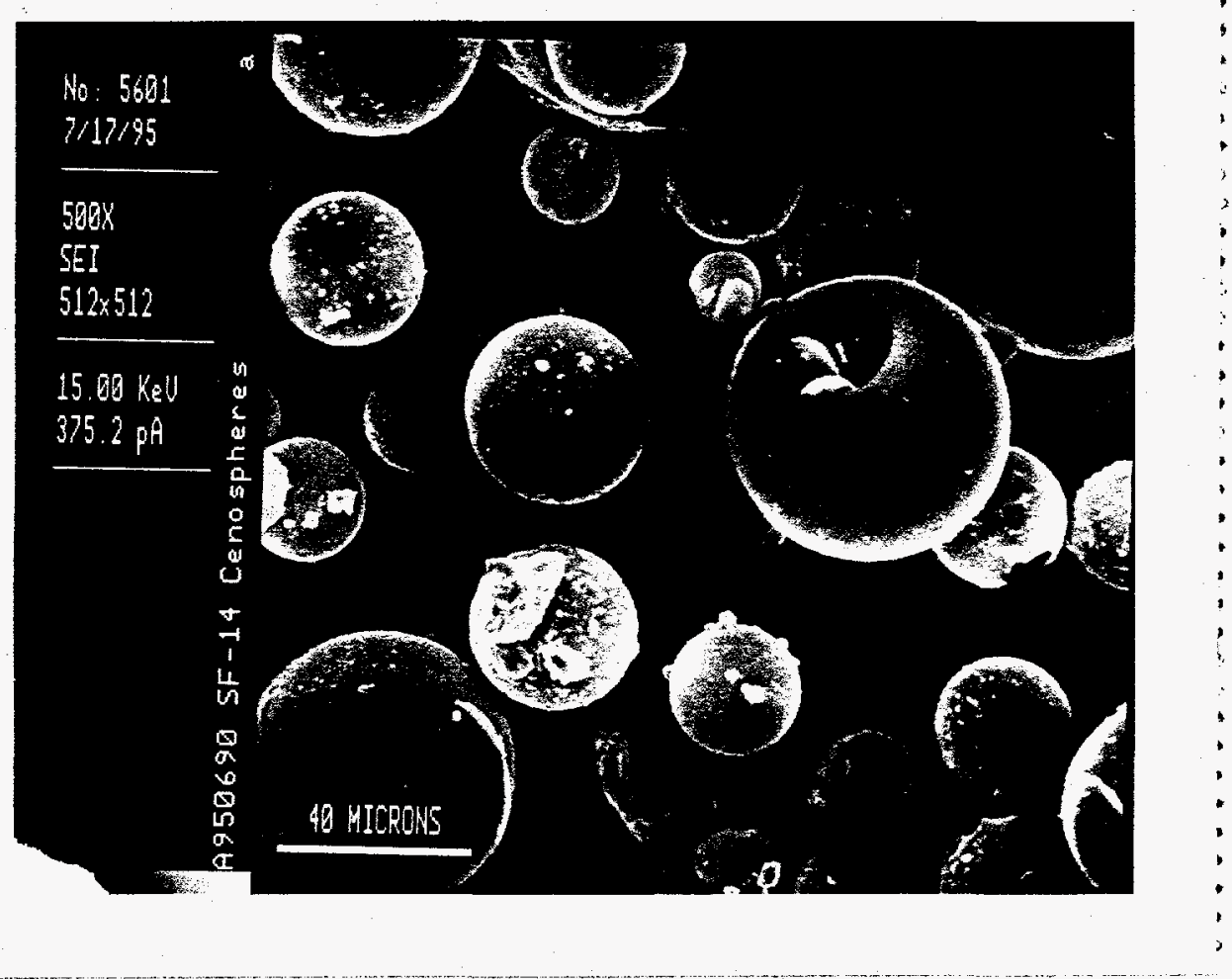

Figure 3. SF-14 cenospheres.

\subsection{RESULTS AND DISCUSSION}

During the course of the project, more than 36 tiles were produced. A rubber molding compound was cast around a tile, and this mold was, in turn, used to form tiles made from composites of resin and ash. Numerous formulations were tried at various solid-to-liquid ratios. The formulations used to produce the trial tiles were made at optimum solid-to-liquid ratios that would allow material handling, yet incorporate the greatest amount of ash for each resin and ash combination. At least two tiles of each possible combination were produced. Trial tiles for strength and morphology were produced from combinations of fly ash, slag, SF-14 cenospheres, and CG cenospheres with acrylic and polyester. Of the cenosphere materials, only specimens of CG and SF-14 were used in the strength and scanning electron microscopy (SEM) examination. During the production of the tiles, differences became apparent between the SF-14 formulations and the CG and SG cenospheres. No differences were noticed between the tiles made with CG and SG cenospheres; the plastic-cenosphere mixture (before hardening) was a viscous, pourable mass. With the SF-14 cenospheres at the same liquid-to-solid ratio, the material behaved more like bread dough and was much more viscous. For workability, the ratio of cenospheres to plastic for the SF-14 had to be lower than for either CG or SG. The cause became apparent after examination of the cenospheres under SEM. CG and SG cenospheres had the appearance of large spherical particles, with CG being slightly larger than SG. SF-14 cenospheres, on the other hand, were noticeably smaller and contained more broken particles but most importantly also contained a larger concentration of smaller particles. The larger spherical particles produced a smoother flowing mass, as would be expected. 
TABLE 1

Plastic-Ash Tile Composition and Properties

\begin{tabular}{|c|c|c|c|c|c|c|c|c|}
\hline Tile No. & Resin & Ash & Weight & $\%$ Ash & \% Plastic & Strength & Sp. Gr. & $\mathrm{P} / \mathrm{L}$ \\
\hline 000 & Ceramic & & 119.6 & & & 3,640 & 2.06 & \\
\hline 001 & Acrylic & Slag & 171.3 & & 100.0 & & & 1.88 \\
\hline 002 & Acrylic & Slag & 177.7 & 60.8 & 39.2 & & & 1.67 \\
\hline 003 & Polyester & Slag & 186.8 & 75.3 & 24.7 & & & \\
\hline 004 & Acrylic & SF-14 & 88 & 22.1 & 77.9 & & & 1.50 \\
\hline 005 & Acrylic & SF-14 & 94.6 & 15.5 & 84.5 & & & 1.78 \\
\hline 006 & Acrylic & SF-14 & 60.6 & 14.6 & 85.4 & 7,170 & 1.05 & 1.78 \\
\hline 007 & Acrylic & CG & 91.2 & & 100.0 & & & 1.60 \\
\hline 008 & Acrylic & CG & 59 & & 100.0 & 5,600 & 0.97 & 1.60 \\
\hline 009 & Acrylic & None & & & 100.0 & & & 2.00 \\
\hline 010 & Polyester & SF-14 & 69.2 & & 100.0 & 8,440 & 1.2 & \\
\hline 011 & Polyester & None & 75 & & 100.0 & 14,000 & 1.9 & \\
\hline 012 & Acrylic & SF-14 & 95.3 & 13.1 & 86.9 & & & 1.36 \\
\hline 013 & Acrylic & Fly ash & 81 & 28.3 & 71.7 & 4,590 & 1.37 & 1.36 \\
\hline 014 & Polyester & None & 78.5 & & 100.0 & 16,390 & 1.18 & \\
\hline 015 & Acrylic & Slag & 117.4 & & 100.0 & & & 1.25 \\
\hline 016 & Acrylic & Slag & & & 100.0 & 2,460 & 1.8 & 1.33 \\
\hline 017 & Acrylic & Slag & 172.5 & 71.4 & 28.6 & & & 1.33 \\
\hline 018 & Polyester & Fly ash & 116.9 & 53.0 & 47.0 & & & \\
\hline 019 & Polyester & Fly ash & 128.1 & 57.6 & 42.4 & & & \\
\hline 020 & Polyester & Fly ash & 107.1 & 64.2 & 35.8 & 4,750 & 1.77 & \\
\hline 021 & Acrylic & None & & & 100.0 & 5,790 & 1.14 & 1.56 \\
\hline 022 & Polyester & CG & 52.5 & 34.3 & 65.7 & 3,850 & 0.93 & \\
\hline 023 & Polyester & CG & 51 & & 100.0 & 3,060 & 1.02 & \\
\hline 024 & Polyester & Slag & 112 & 78.5 & 21.5 & 2,970 & 2.04 & \\
\hline 025 & Acrylic & SG & 83.9 & 14.2 & 85.8 & & & 1.36 \\
\hline 026 & Acrylic & SG & & 24.6 & 75.4 & & & 1.36 \\
\hline 027 & Acrylic & SG & 83.3 & 29.7 & 70.3 & & & 1.18 \\
\hline 028 & Acrylic & SG & 87.6 & 34.5 & 65.5 & & & 1.00 \\
\hline 029 & Acrylic & SF-14 & 103.2 & 37.8 & 62.2 & & & 0.57 \\
\hline 030 & Acrylic & SF-14 & 83.6 & 59.8 & 40.2 & & & 0.42 \\
\hline 31 & Acrylic & SF-14 & 65.4 & & 100.0 & & & \\
\hline 032 & Polyester & SF-14 & 107.6 & & 100.0 & & & \\
\hline 033 & Polyester & SG & 106 & & 100.0 & & & \\
\hline 034 & Composite & CG & 83.4 & 41.4 & 58.6 & & & 1.00 \\
\hline 035 & Polyester & SF-14 & 98.9 & & 100.0 & & & \\
\hline 036 & Polyester & SF-14 & 111 & & 100.0 & & & \\
\hline
\end{tabular}


TABLE 2

Plastic-Ash Tile Selected Physical Properties

\begin{tabular}{cllcccc}
\hline Sample & Polymer & Ash & $\begin{array}{c}\text { Dry Unit } \\
\text { Weight, pcf }\end{array}$ & $\begin{array}{c}\text { Wet Unit } \\
\text { Weight, pcf }\end{array}$ & $\begin{array}{c}\text { Modulus of } \\
\text { Rupture, psi }\end{array}$ & $\begin{array}{c}\text { Bulk } \\
\text { Specific } \\
\text { Gravity }\end{array}$ \\
\hline Control & & & 119.6 & 131.5 & 3,640 & 2.06 \\
021 & Acrylic & & 65.5 & 65.5 & 5,790 & 1.14 \\
008 & Acrylic & CG & 59 & 59.1 & 5,600 & 0.97 \\
013 & Acrylic & Fly ash & 81 & 81 & 4,590 & 1.37 \\
006 & Acrylic & SF-14 & 60.6 & 60.7 & 7,170 & 1.05 \\
016 & Acrylic & Slag & 105.1 & 105.1 & 2,460 & 1.8 \\
014 & Polyester & & 78.5 & 78.5 & 16,390 & 1.18 \\
022 & Polyester & CG & 52.5 & 52.6 & 3,850 & 0.93 \\
020 & Polyester & Fly ash & 107.1 & 107.4 & 4,750 & 1.77 \\
010 & Polyester & SF-14 & 69.2 & 69.3 & 8,440 & 1.2 \\
024 & Polyester & Slag & 112 & 112.1 & 2,970 & 2.04 \\
\hline
\end{tabular}

Thus in a mix where this might be a consideration for reasons of material handling, CG and SG cenospheres would be more desirable than SF-14. Through trial and error, the maximum volume of ash based on handling properties was used for the final set of tiles. In formulating tiles, all of the materials were measured by volume because of the varying bulk densities for ease of material handling during formulation. After production, mass of ash-to-plastic ratios were determined by weighing ash remaining after heating to pyrolyze the plastic. One of each specimen, including control tiles consisting of polymer only, was broken to determine strength, and the remains from this testing were used for SEM examination.

\subsection{Morphology}

\subsubsection{Raw Materials}

The three different types of cenospheres and the fly ash were examined by SEM for their morphological characteristics. Figures 1 through 4 are the SEM photomicrographs of these materials. Observations than can be readily made include the relatively uniform size exhibited by the CG (Figure 1) and SG (Figure 2) cenospheres. The SG cenospheres (Figure 2) also show a number of broken and smaller grains than found in the CG cenosphere sample. The SF-14 cenospheres (Figure 3) show a smaller average size along with a greater size distribution than the other cenospheres. The fly ash (Figure 4) shows the greatest size distribution of all of these materials. 


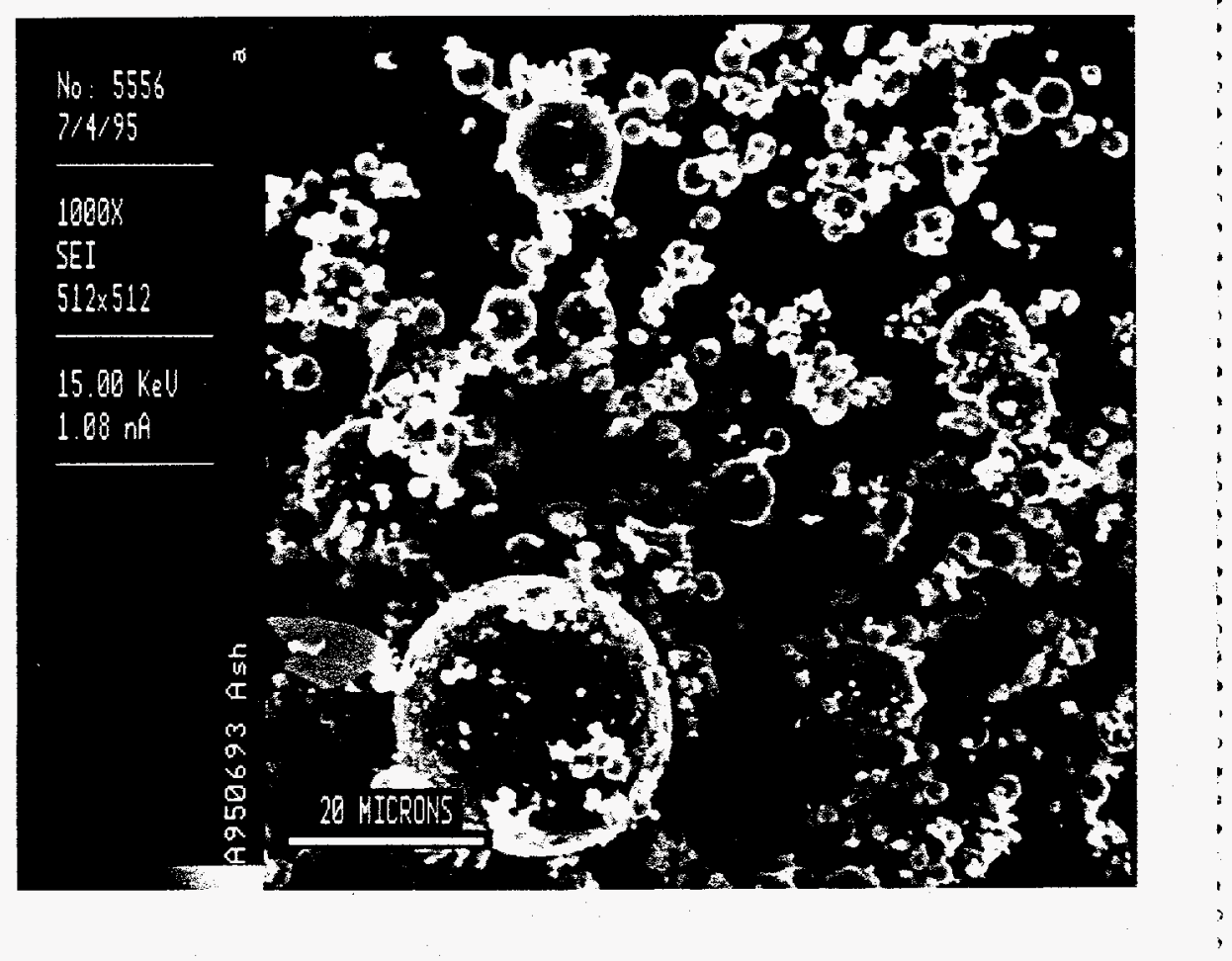

Figure 4. Ash.

The SEM photomicrograph of the cenospheres (Figures 1-3) were all taken at a $500 \times$ magnification. The field of view for these figures is approximately $180 \mu \mathrm{m}(0.18 \mathrm{~mm})$. The SEM photomicrograph of the fly ash (Figure 4) was taken at a magnification of $1000 \times$ with the field of view being approximately $90 \mu \mathrm{m}(0.09 \mathrm{~mm})$. Direct size comparisons cannot be made between the fly ash (Figure 4) and the cenospheres (Figures 1-3), but the much smaller grain size and fineness of the fly ash can be noted.

The slag was excluded from SEM morphological characterization because of the large size of the particles. Cut and fractured surfaces of the tiles made with slag will be discussed in the following section.

\subsubsection{Cut Surfaces}

Examination of the cut surface of the tiles was considered to be an important part of the morphological characterization to determine if the cenospheres improve the binding capabilities of the surface by providing numerous indentations of the surface for the bonding medium to flow into. The first sample selected was cut with a small lapidary saw and left unpolished. Figure 5 shows the secondary electron image from the acrylic tile with SF-14 cenospheres. The scratch marks left by the saw are readily visible. Figure 6 is a backscattered electron image of the same area shown in Figure 5. A backscattered electron image is acquired by the electrons "bouncing off" the sample, giving those compounds with a higher atomic number a brighter color. Since the acrylic is of a very low atomic number and the cenospheres are considerably higher, the cenospheres or any portion of them will be much brighter in the image. Figure 6 shows that most of what appears to be 


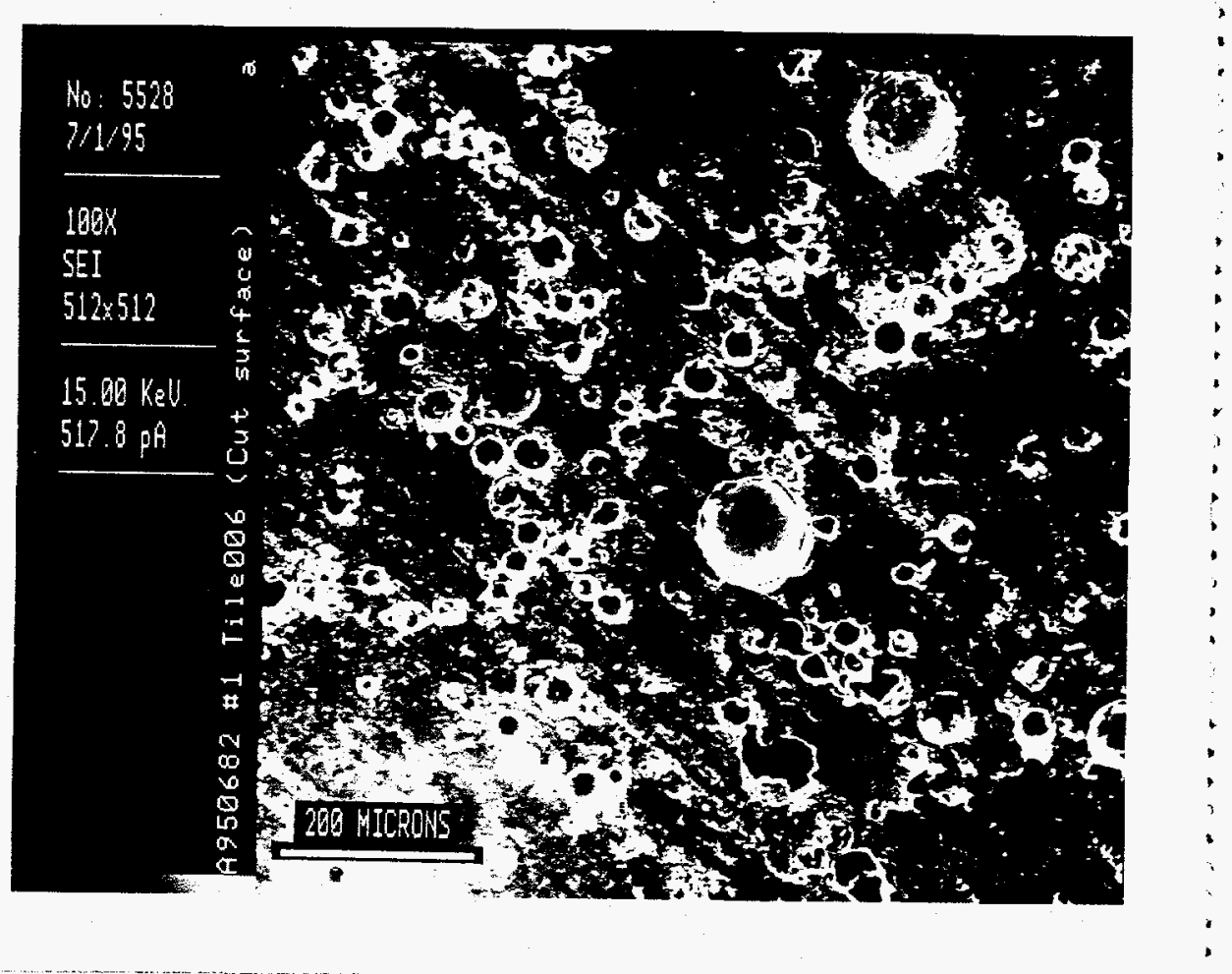

Figure 5. \#1 Tile 006 (cut surface).

cenospheres in Figure 5 are either air bubbles in the acrylic or cenospheres that are plucked out. Very few cenospheres remained in place after cutting.

A polished surface of the same tile, acrylic with SF-14 cenospheres, was also prepared and examined. The surface was prepared by polishing in several stages with finer polishing grit down to the final $0.5-\mu \mathrm{m}$ polishing compound. The polished surface (Figure 7 ) reveals more detail than the cut surface (Figure 5). Figure 8 is the backscattered image from the same area as Figure 7, showing that very few cenospheres were plucked out during the polishing process. A comparison to Figure 6 indicates that polishing is the proper way to expose cenospheres when preparing a surface for bonding.

Figures 9 and 10 are the secondary electron image and the backscattered electron image of the polished sample from the acrylic and CG cenospheres tile. The field of view is approximately $875 \mu \mathrm{m}(0.875 \mathrm{~mm})$ for these images, as well as in Figures 11 and 12. Again, the size difference between the CG and SF-14 cenospheres is readily apparent. The backscattered images (Figures 10 and 12) again show that for maximum cenosphere exposure, the surface should be polished.

Figures 13 and 14 are secondary and backscattered electron images of the polished sample of the slag in acrylic. Because of the large size of the slag particles, a much lower magnification $(20 \times)$ was used to show the particle size, shape, and distribution of the slag. The field of view for Figures 13 and 14 is approximately $4.5 \mathrm{~mm}$. These images show less binding (acrylic) material and more slag than the previous tiles with cenospheres. 


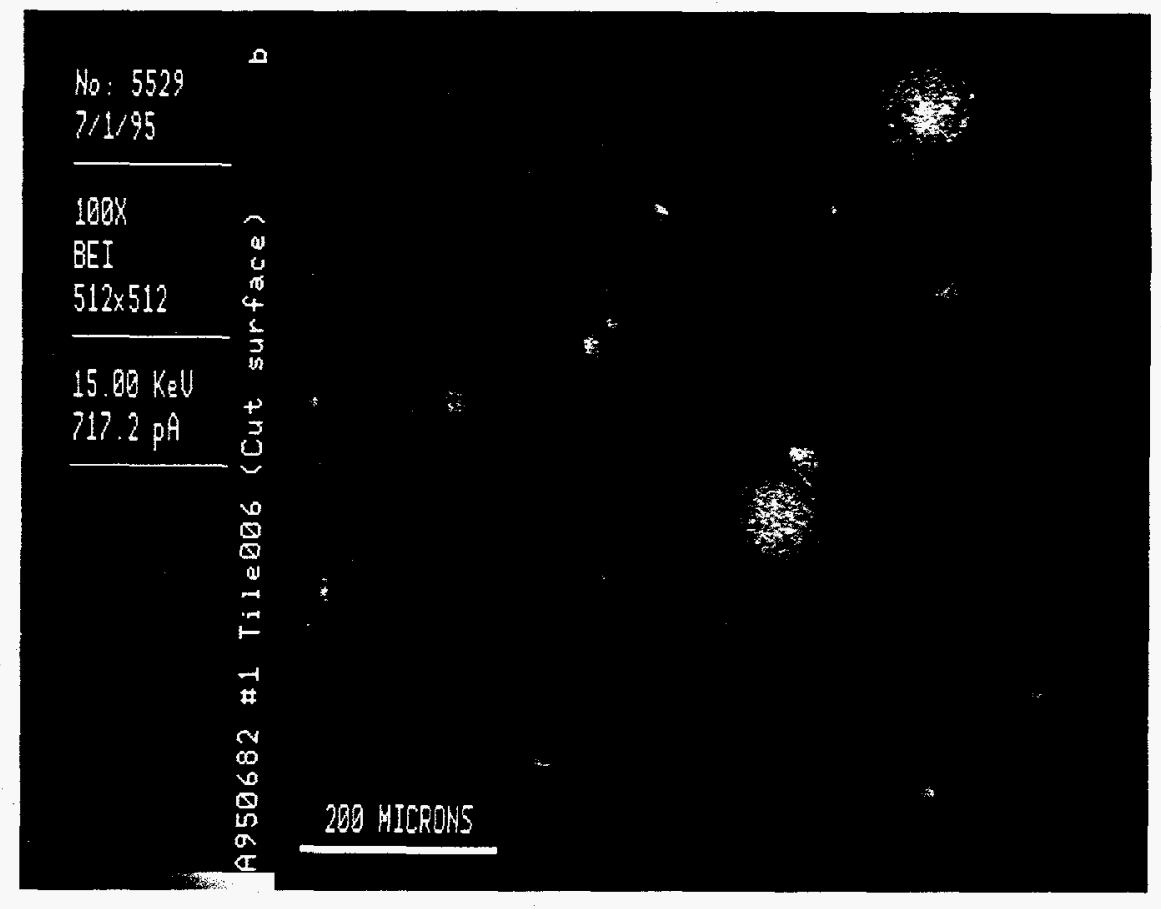

Figure 6. \#1 Tile 006 (cut surface).

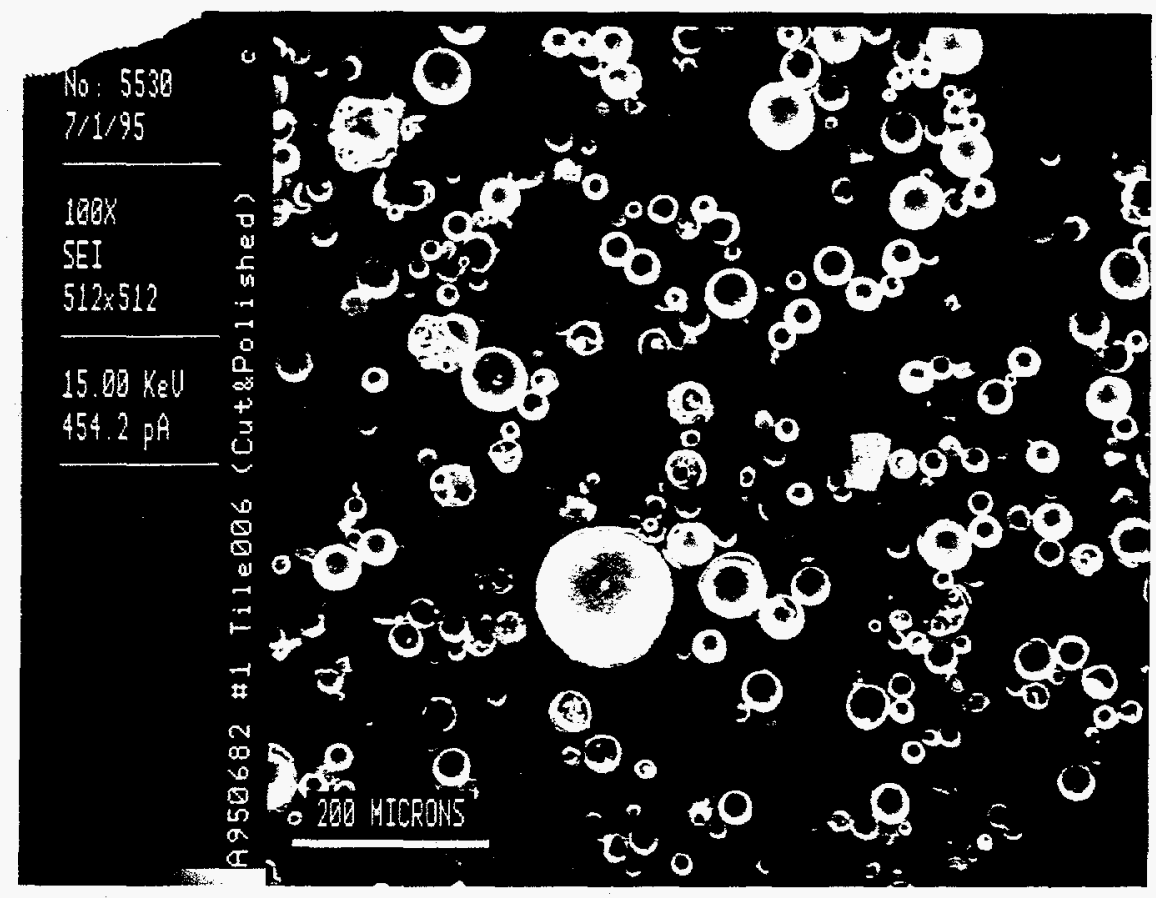

Figure 7. \#1 Tile 006 (cut and polished). 


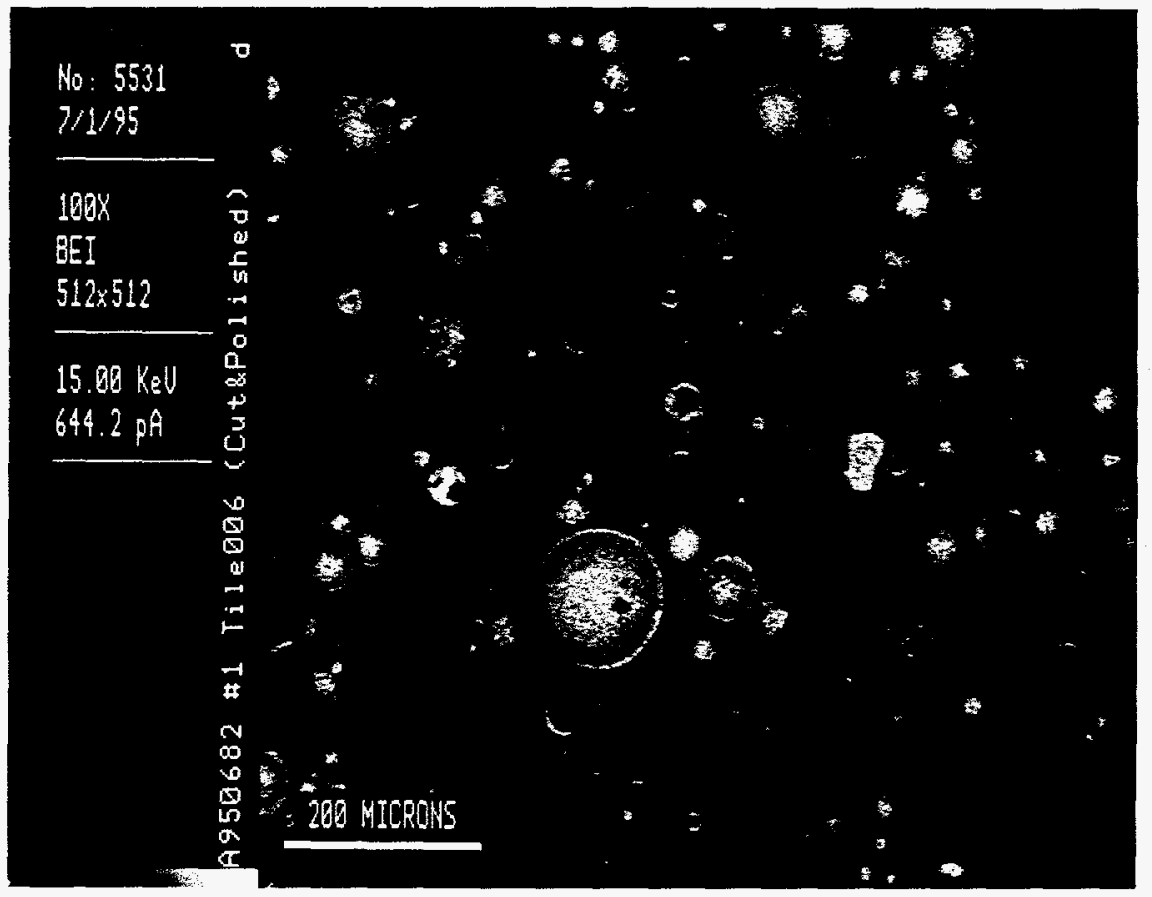

Figure 8. \# 1 Tile 006 (cut and polished).

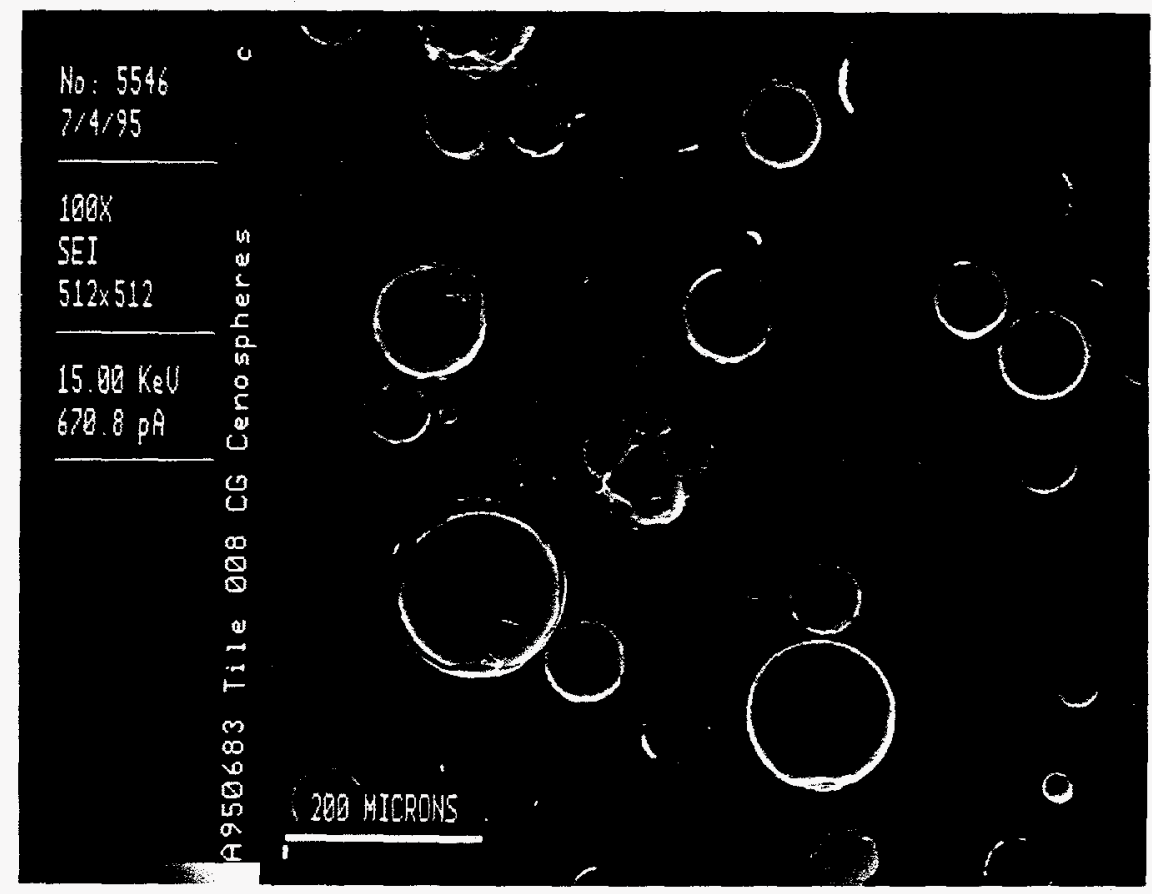

Figure 9. Tile $008 \mathrm{CG}$ cenospheres. 


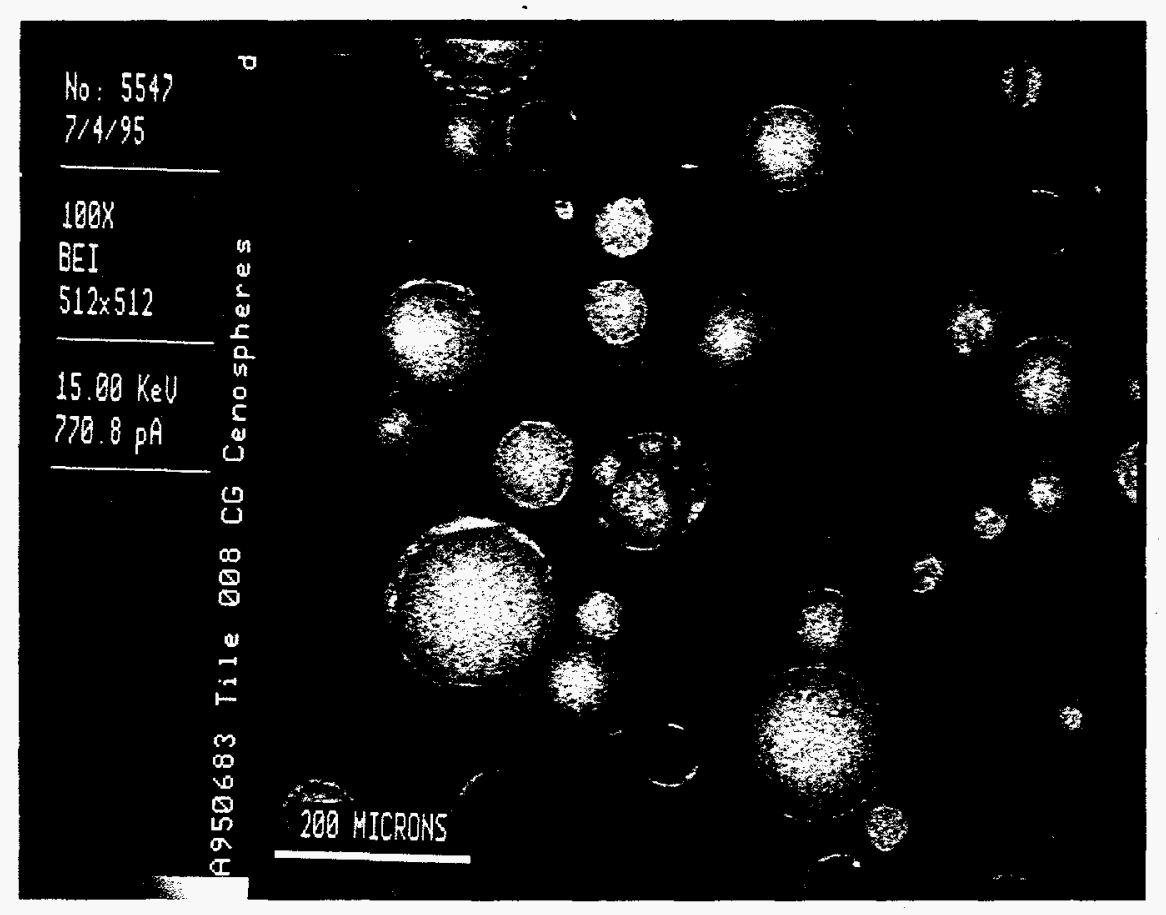

Figure 10. Tile $008 \mathrm{CG}$ cenospheres.

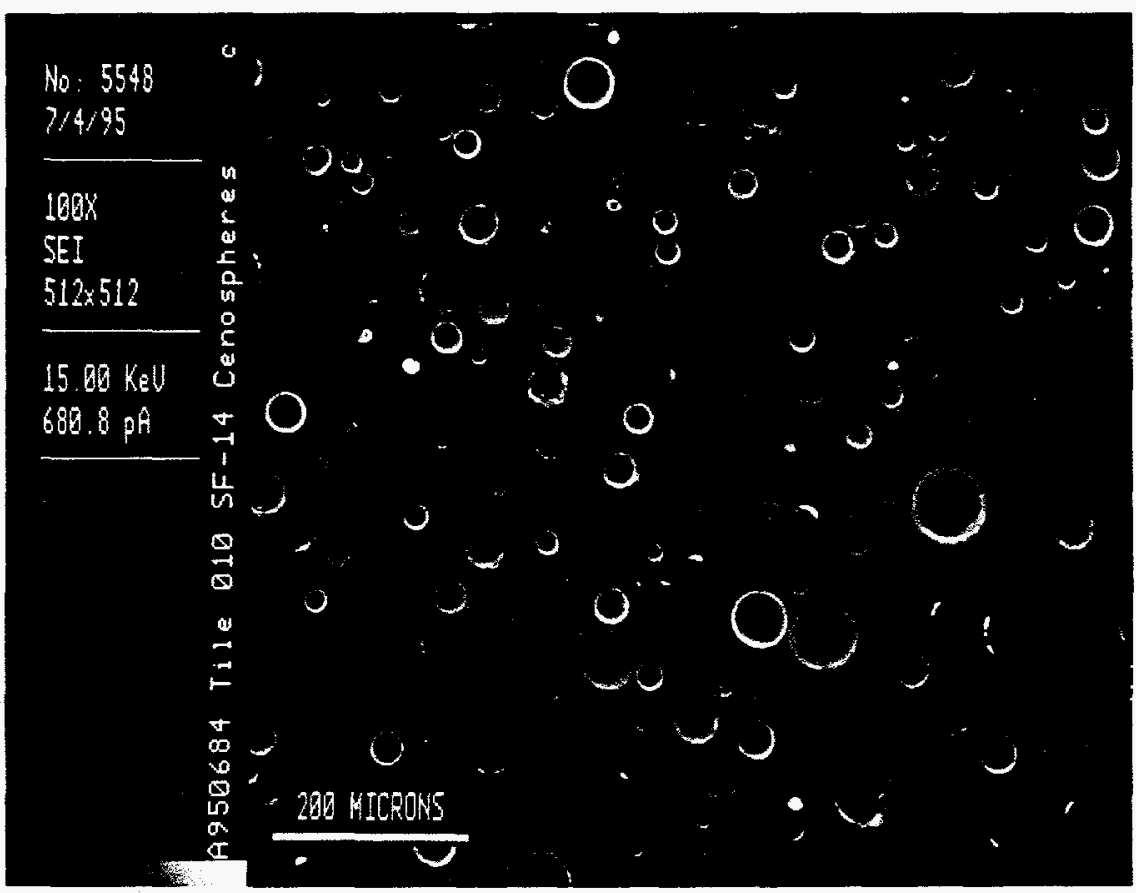

Figure 11. Tile 010 SF-14 cenospheres. 


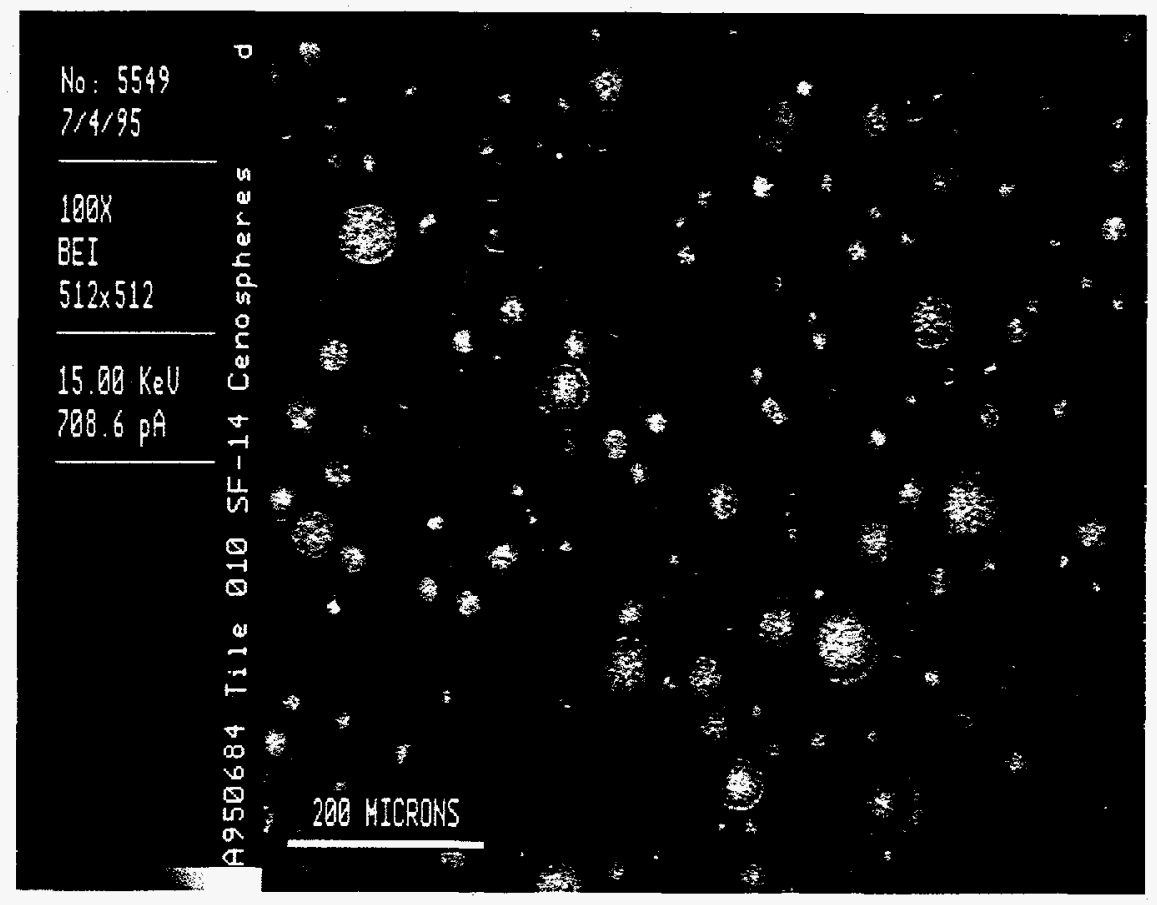

Figure 12. Tile 010 SF-14 cenospheres.

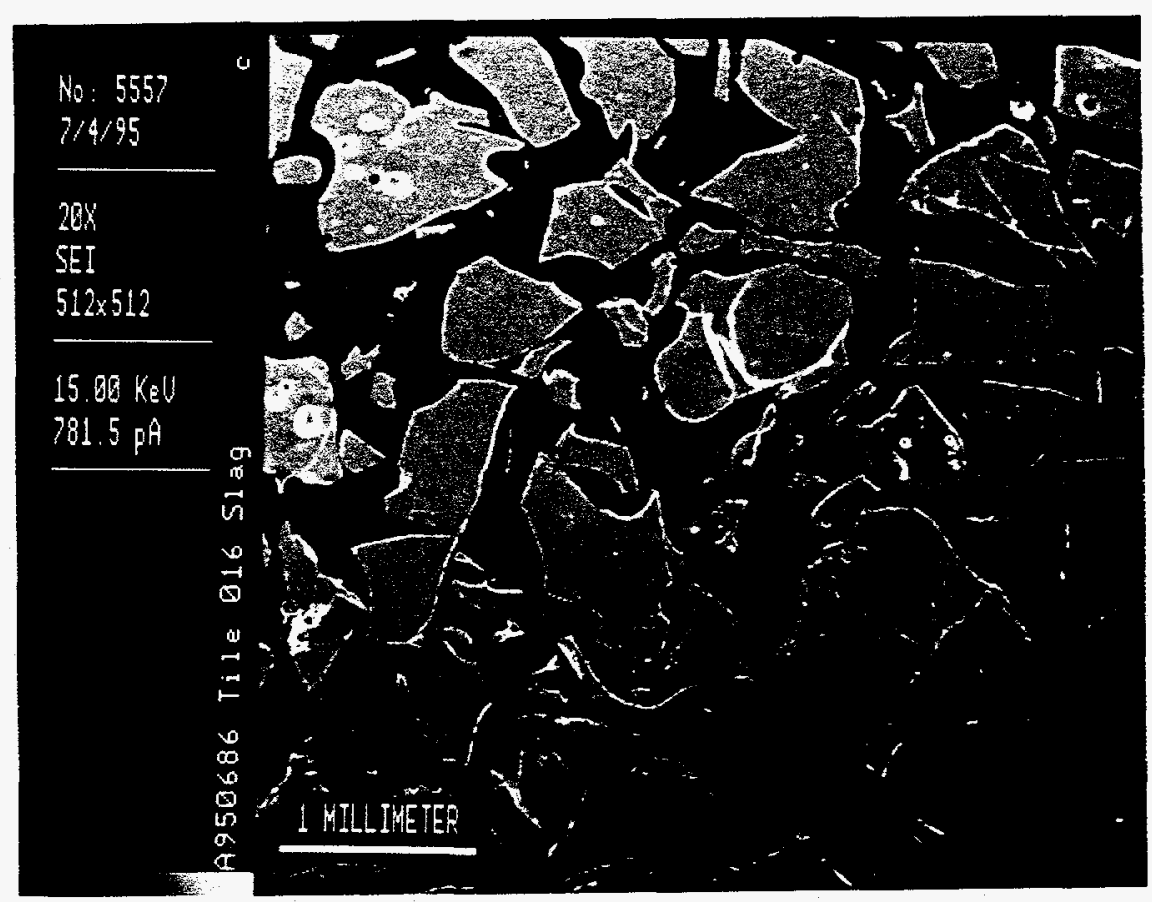

Figure 13. Tile 016 slag. 


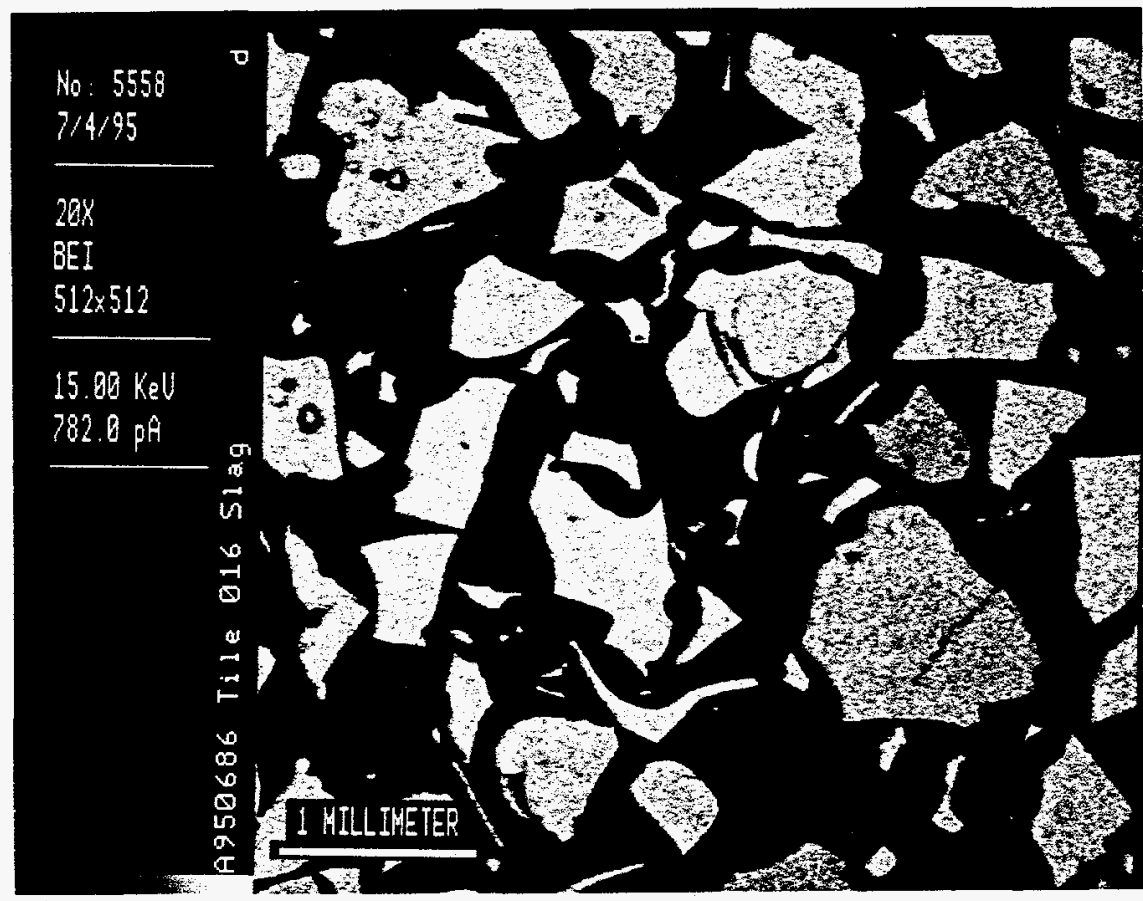

Figure 14. Tile 016 slag.

Figures 15 and 16 show the polished surface of the polyester and fly ash tile. These photomicrographs were taken at a $500 \times$ magnification showing a field of view of approximately 180 $\mu \mathrm{m}(0.18 \mathrm{~mm})$. Figure 15 shows both solid fly ash particles and a few cenospheres, all of variable sizes. Because of the wide variation in size of the fly ash grains, the grains can pack much closer together, requiring less binding material. Figure 16, the backscattered image of the same area as Figure 15, shows that very few grains were plucked out during the cutting and polishing process.

\subsubsection{Fracture Surfaces}

Figures 17 through 26 are fracture surfaces of the tiles. A small portion of the fracture surface created when the tiles were subjected to strength testing was examined by SEM. Both secondary and backscattered electron images were taken to determine if the fractures would go around or through individual grains. In most cases, the fractures went around the particles, leaving indentations and exposed particles. This indicates that these types of fillers did not improve the strength characteristics of the tiles.

\subsection{Physical Properties of the Tiles}

The primary differences in the various tiles were in appearance, bulk density, and strength. Figure 27 shows examples of the tiles produced and gives an indication of the differences in appearances. Table 1 lists the tiles in numerical order with select attributes. Table 2 is a subset of Table 1 where tiles have been sorted by ash additive and ordered in decreasing strength. Several trends become apparent in Table 2. First, with one exception, polyester tiles gave greater strengths 


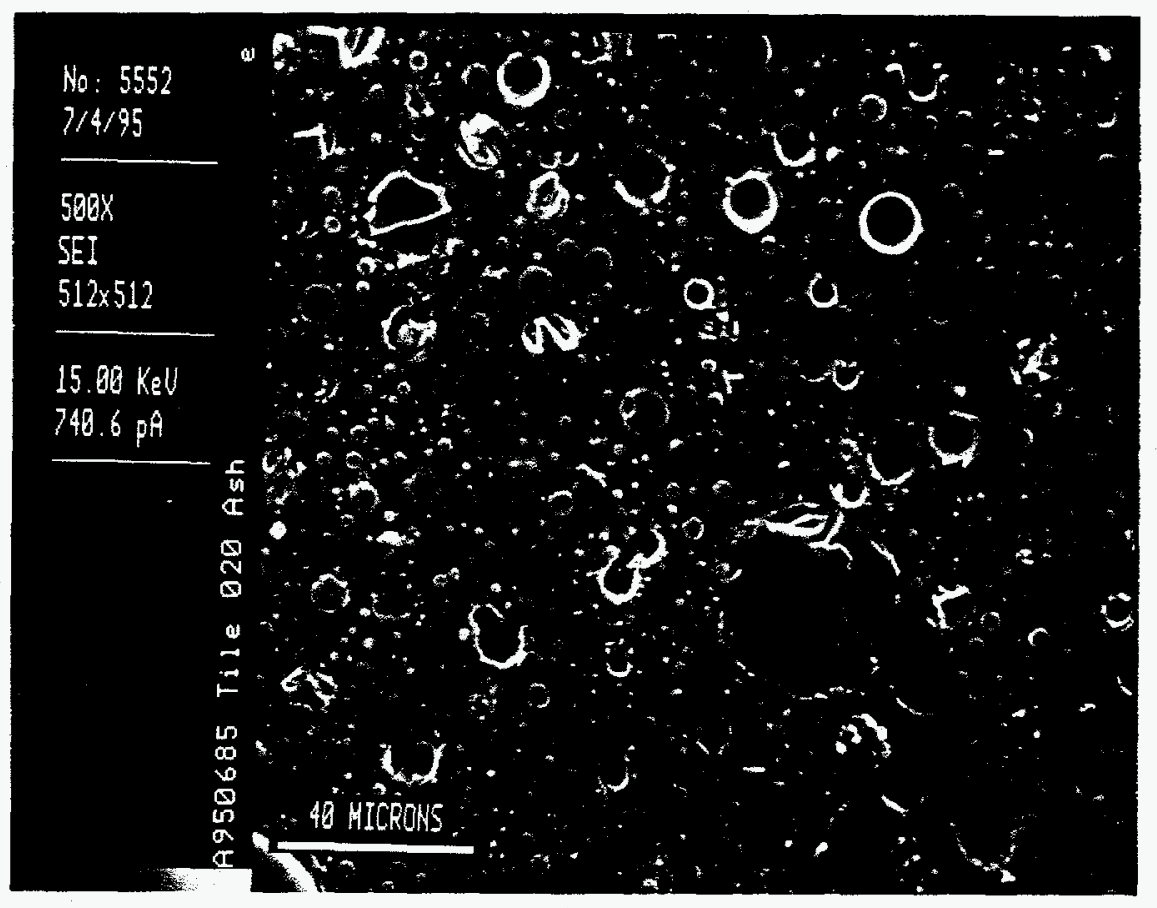

Figure 15. Tile 020 ash.

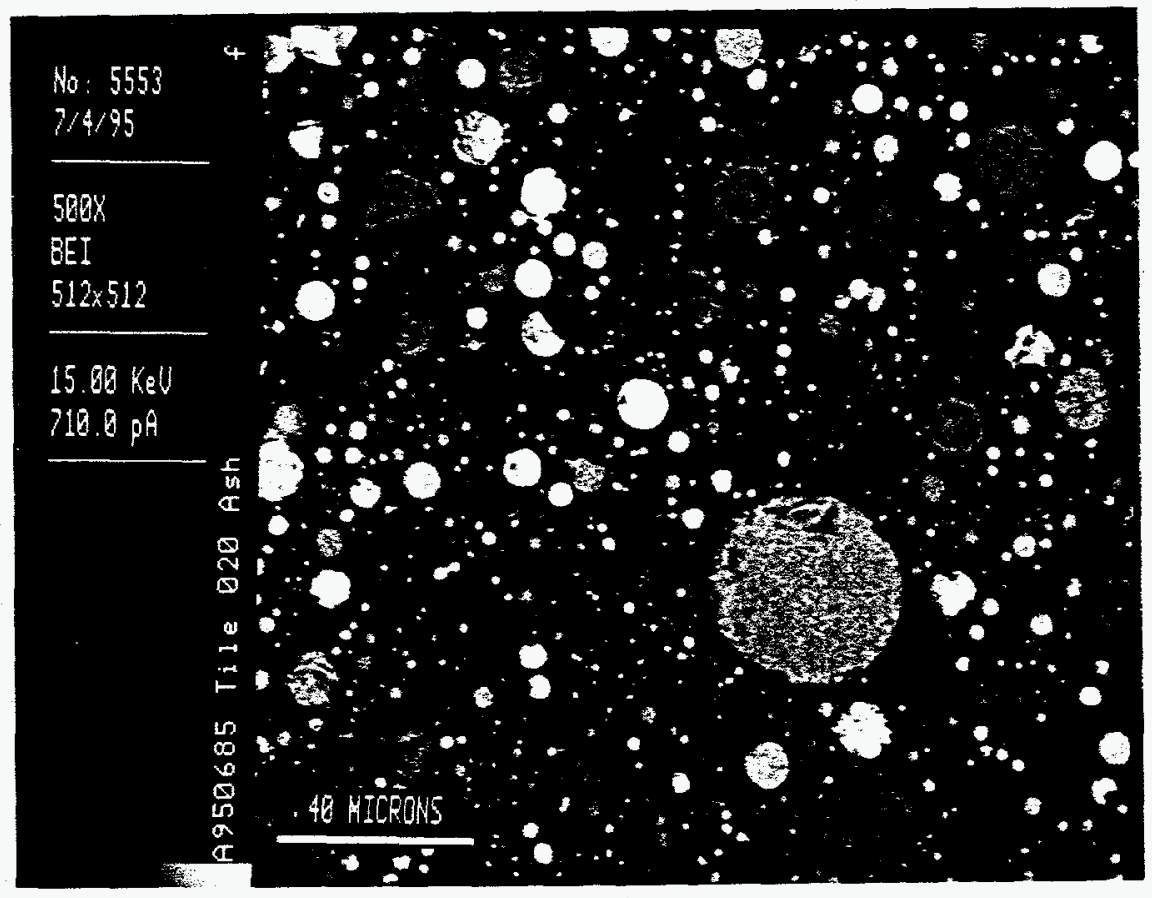

Figure 16. Tile 020 ash. 


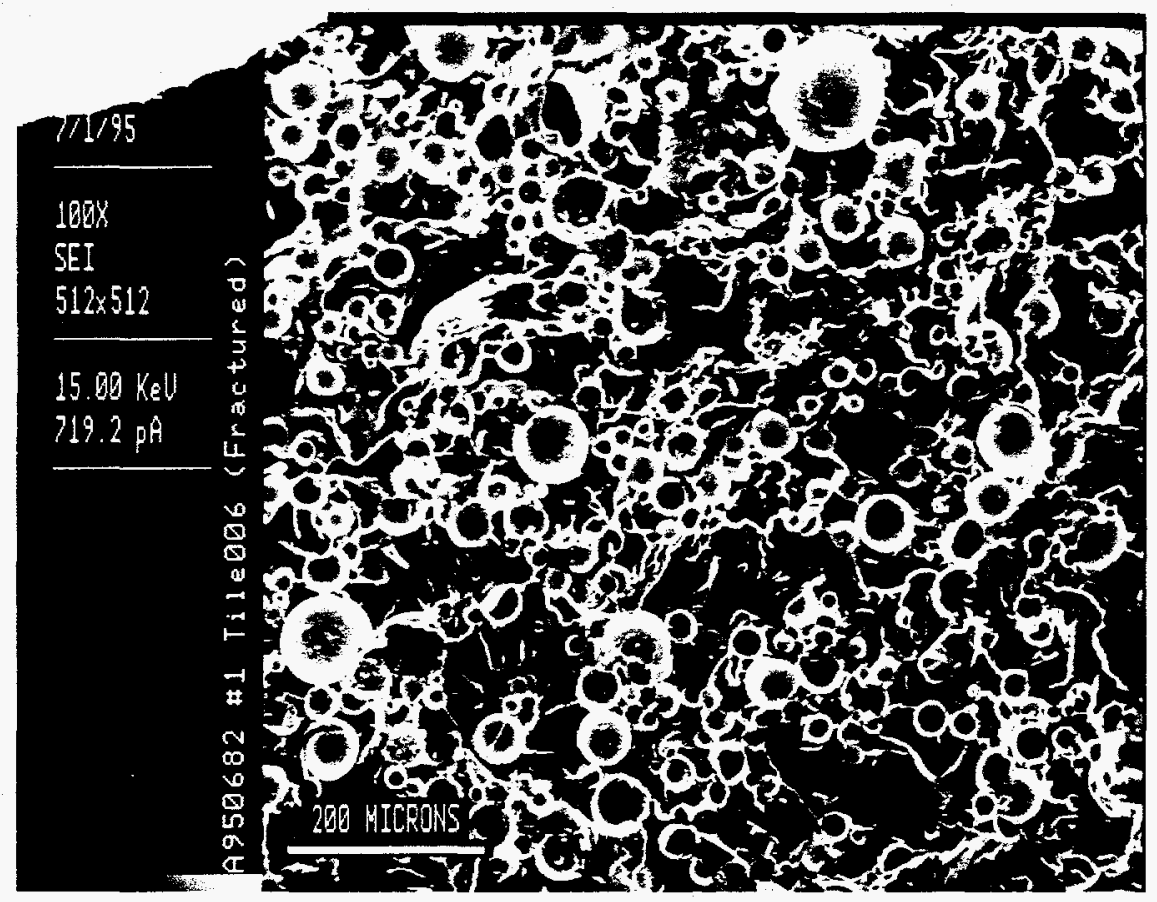

Figure 17. \#1 Tile 006 (fractured).

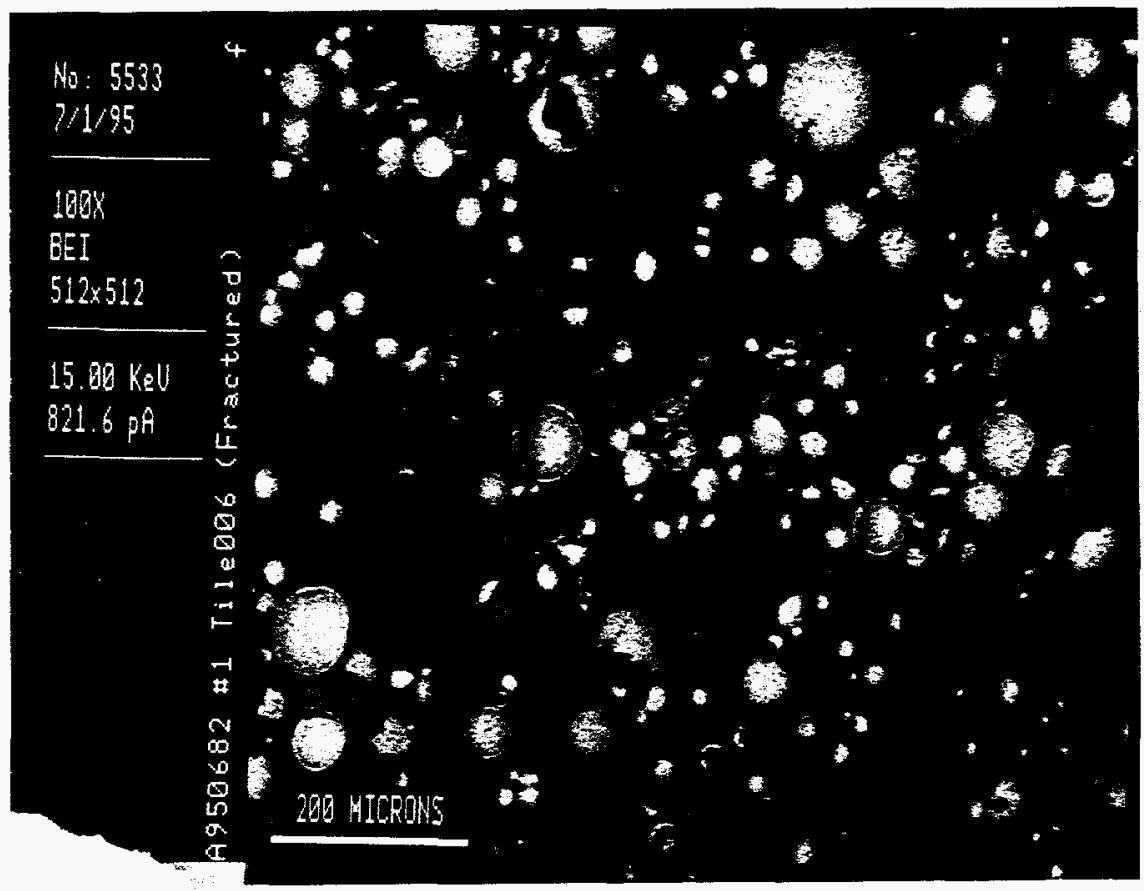

Figure 18. \#1 Tile 006 (fractured). 


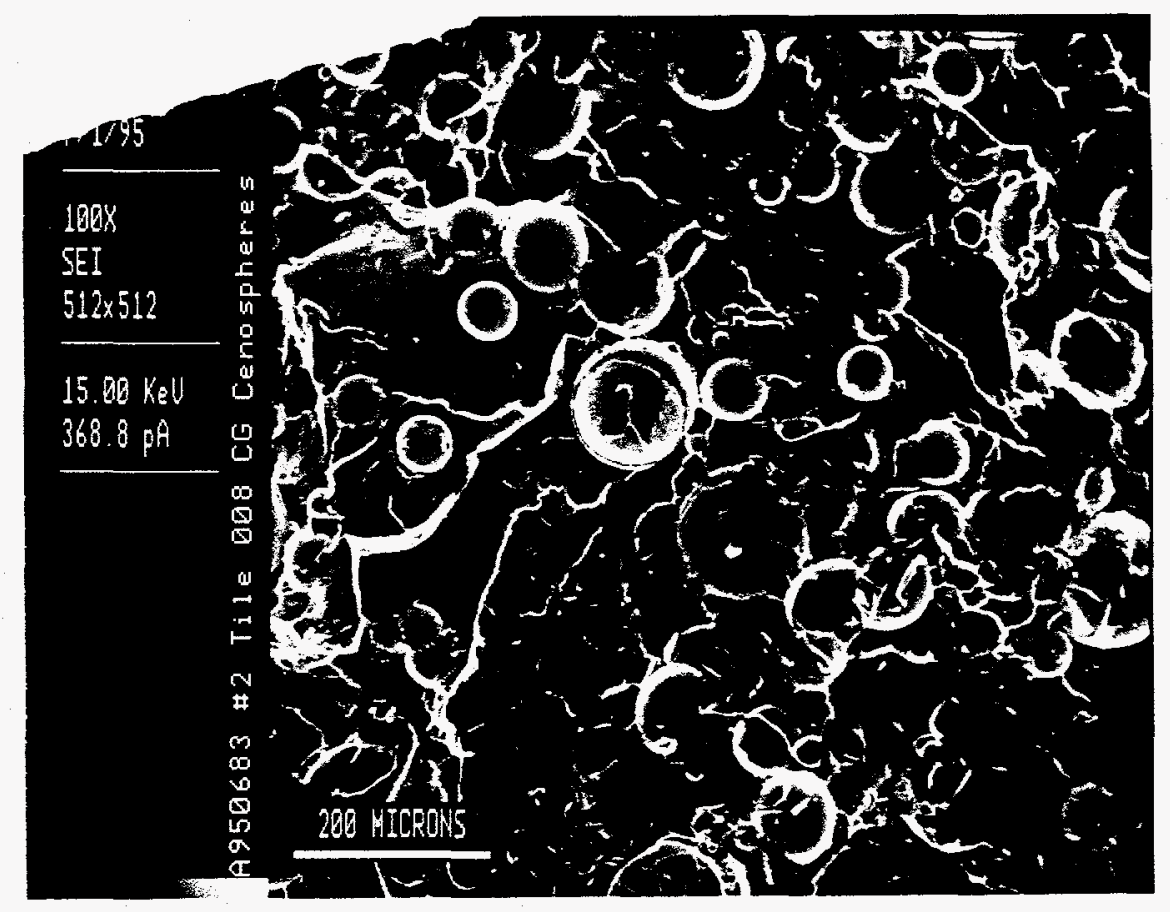

Figure 19. \#2 Tile $008 \mathrm{CG}$ cenospheres.

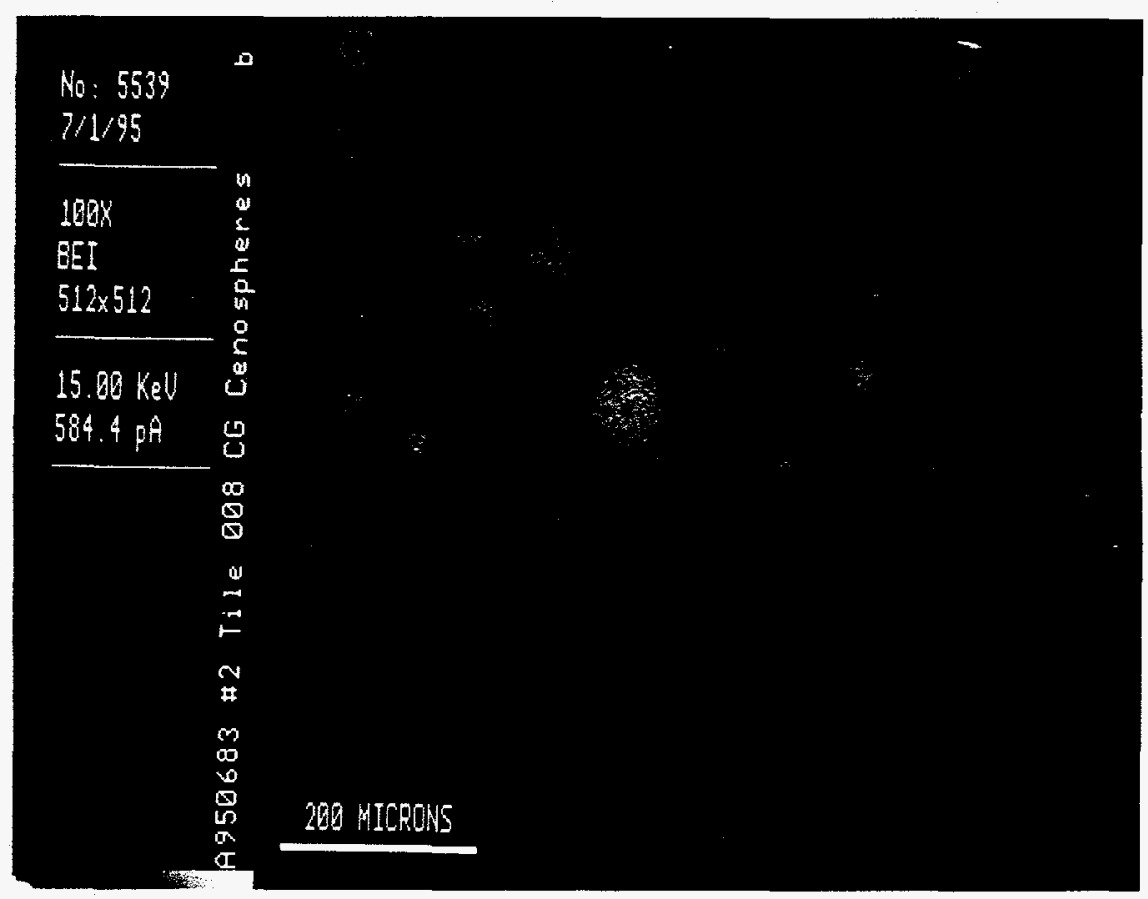

Figure 20. \#2 Tile $008 \mathrm{CG}$ cenospheres. 


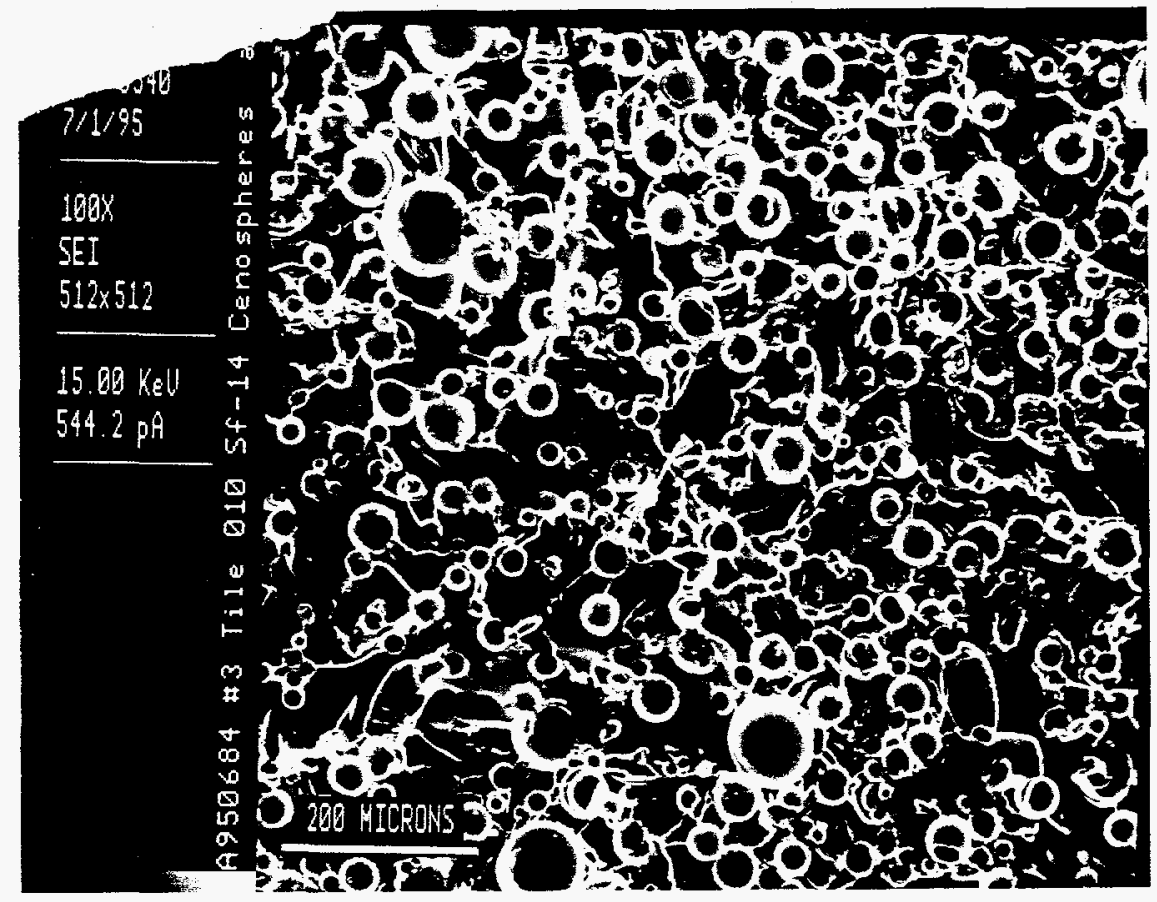

Figure 21. \#3 Tile 010 SF-14 cenospheres.

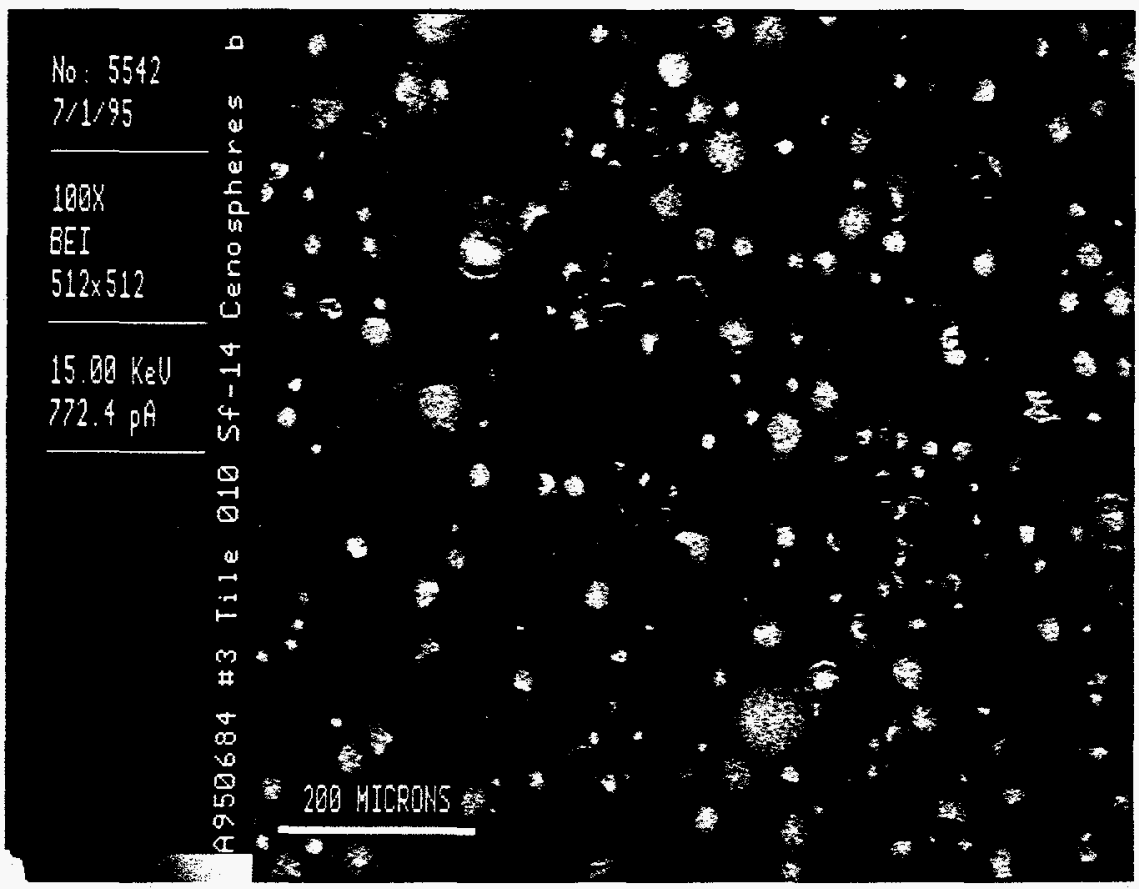

Figure 22. \#3 Tile 010 SF-14 cenospheres. 
of

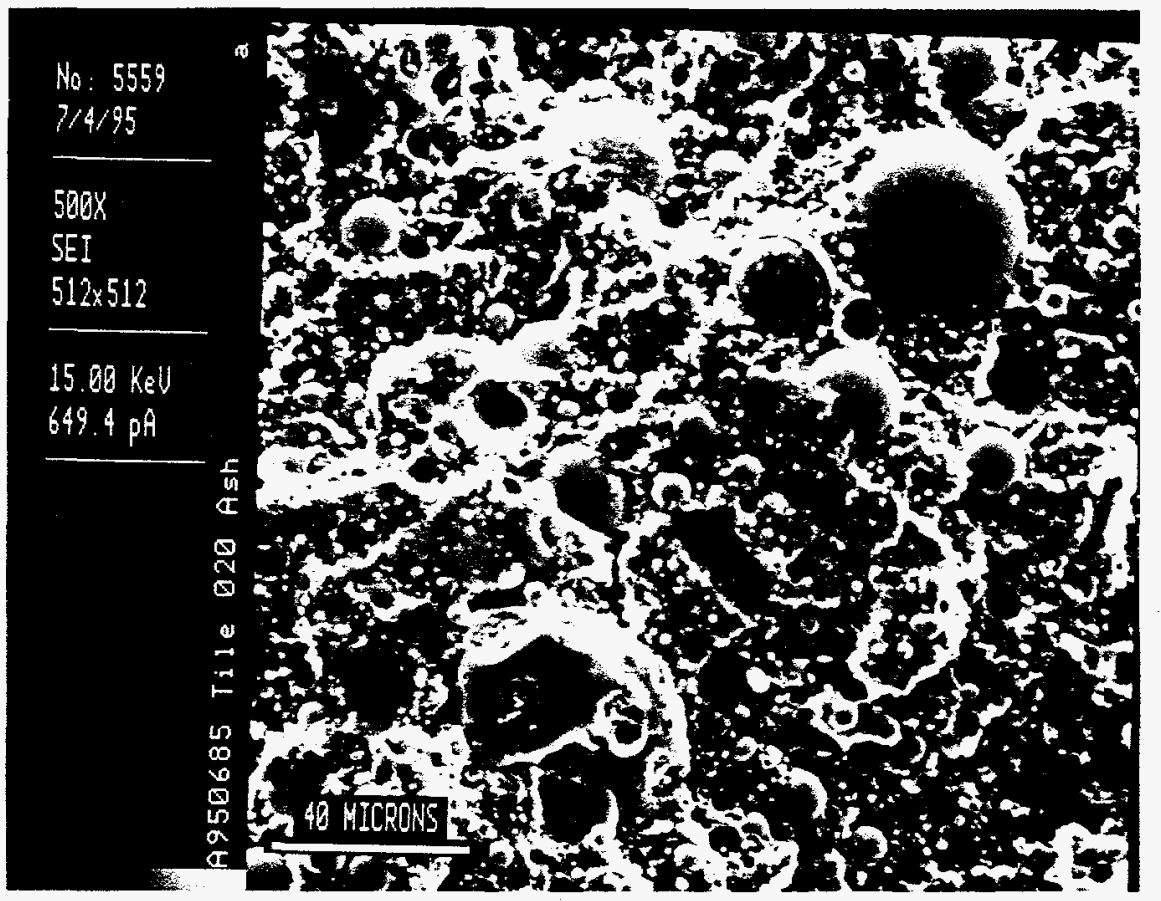

Figure 23. Tile 020 ash.

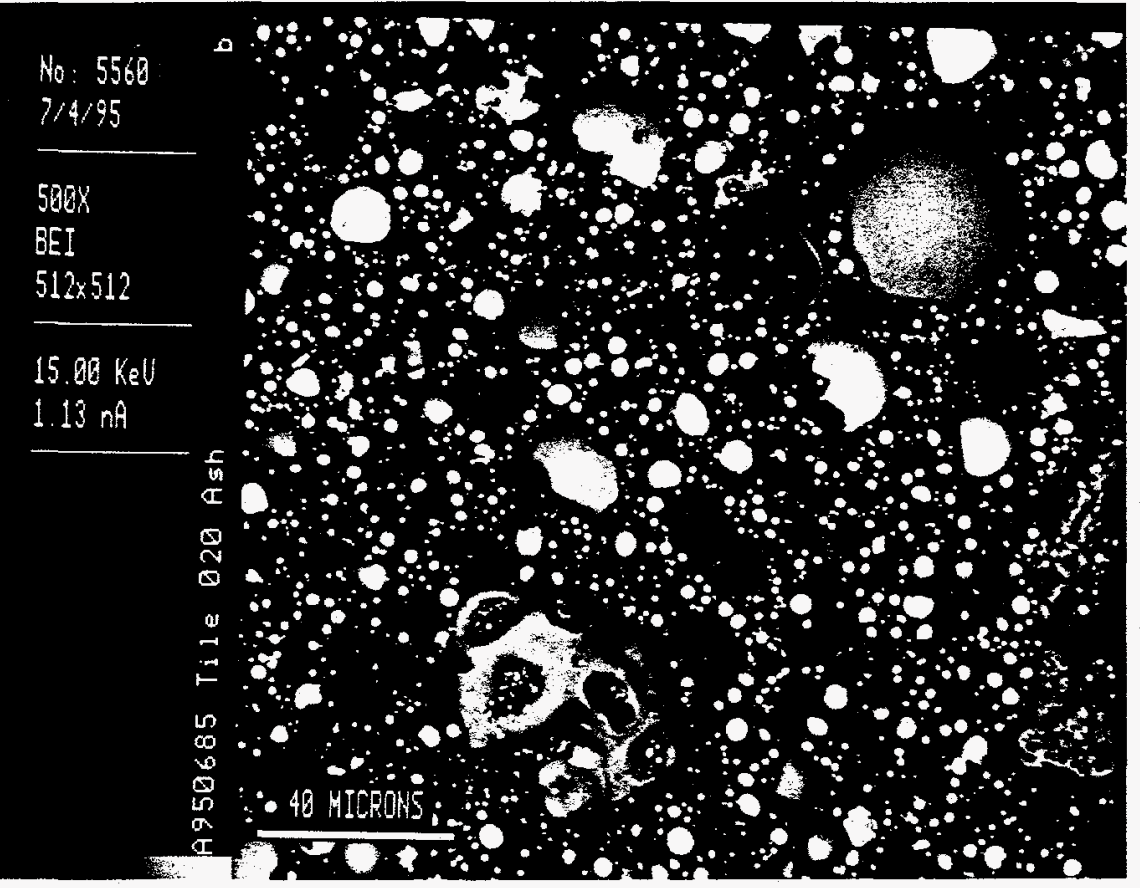

Figure 24. Tile 020 ash. 


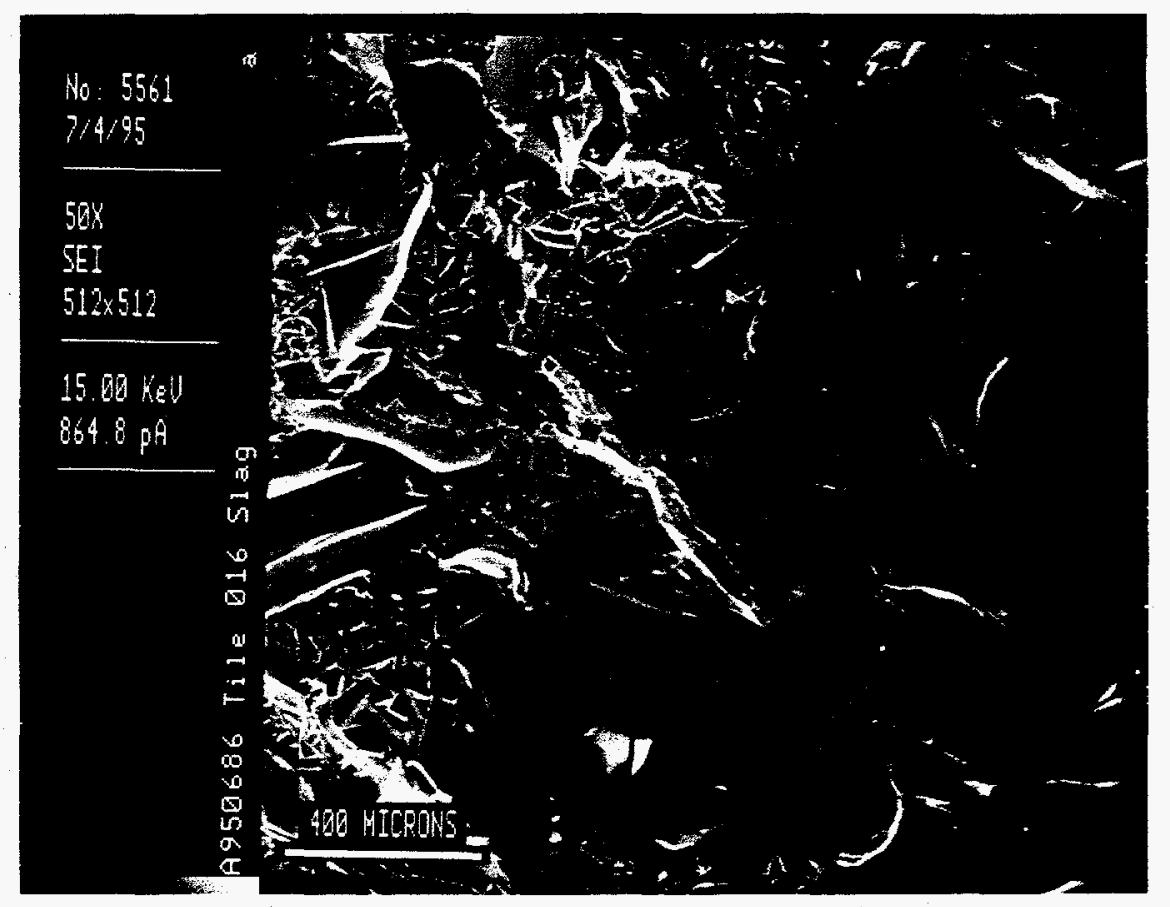

Figure 25. Tile 016 slag.

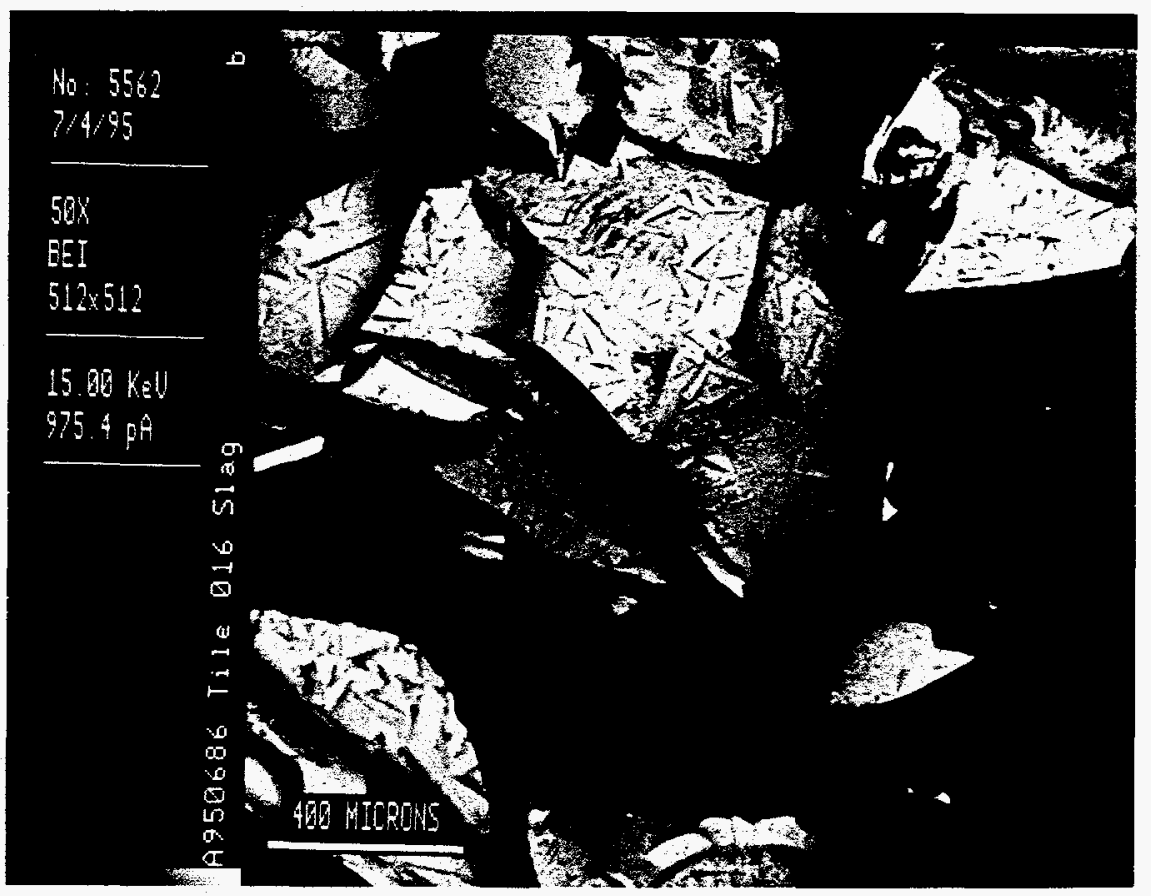

Figure 26. Tile 016 slag. 

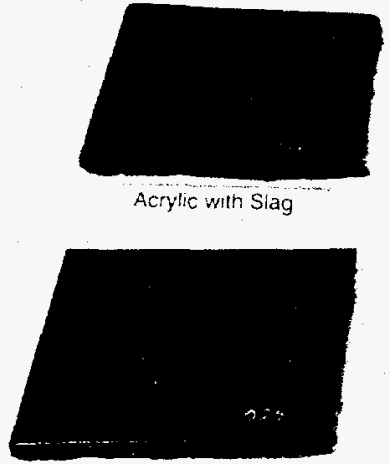

Polyester with Slag

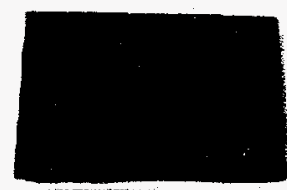

Acrylic with Ash

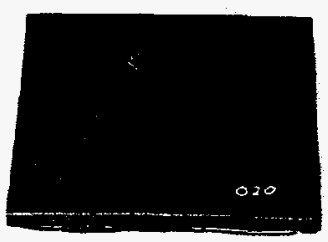

Polyester with Ash

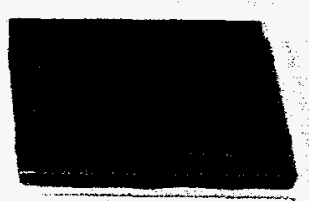

Acrylic with

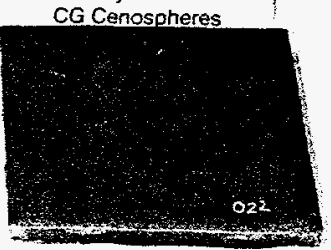

Polyester with CG Cenospheres

Figure 27. Examples of plastic-ash tiles

than acrylic. The one exception is with CG cenospheres. Second, slag yielded the lowest strength, followed by CG cenospheres, fly ash, and SF-14. The tile produced from plastic alone provided the highest strengths. It can also be seen that acrylic was the least affected by additives. The reasons for these trends in strength can only be speculated at this time, although the addition of particulate additives would be expected to reduce the strength of most binding materials. Investigation of exact reasons for strength reduction was beyond the scope of the project. It should be noted that, with the exception of the addition of slag, all of the tiles had greater strength than the ceramic control tile. The addition of SF-14 cenospheres gave a tile with twice the strength of ceramic and half the bulk density. The addition of CG cenospheres provided less than half the bulk density, with tiles lighter than water, but had only a small strength advantage. With advanced molding equipment, it is expected that a much higher mass of cenospheres could be used with further reduction in bulk density. It is not known what influence this would have on strength.

The addition of coal-combustion by-products (CCB) to plastic provides an additional option for formulation of new composite materials. This is the incorporation of properties of ash in polymeric materials. Ash is known to be both pozzolanic and cementitious. Cementitious reactions can occur in these two forms in ash. Pozzolanic CCBs give rise to strength formation in mixes with lime, and water and $\mathrm{CCBs}$ that are cementitious materials provide strength with the addition of water only. This leads to some interesting speculation with composite materials. Although beyond the scope of this project, there is a possibility that the cementitious and pozzolanic properties of CCBs could exist at the fractured or cut surface of a polymer CCB composite by exposing fresh CCB surfaces. This would give rise to a plastic composite that would give adhesion with cement-based grouts and adhere to setting cement surfaces. Additionally, the addition of cenospheres could give rise to enhanced bonding properties of a cut composite surface by providing concave surfaces as well as undercut 
surfaces that would provide bonding sites in polymers not normally amenable to bonding with common adhesives. Wearability and scuff resistance of acrylic and polyester with cenospheres would likely be poor since the material formed a powder on scratching and was easily marked. This property was used to identify tiles by marking using an engraver. Polyester with fly ash, however, appeared to be somewhat scratch-resistant. With slag addition, a material was formed that had a rough surface, which should provide excellent adhesion and antiskid properties on potentially slippery surfaces and areas. Although the apparent scuff resistance of the cenosphere and ash composites, especially with acrylic resin, was such that floor application would be unlikely, the slag composites had properties that might make floor application a suitable option. The application of polyester ash blends in flooring applications might be a topic for further investigation.

There are undoubtedly numerous applications for light, strong, nonconductive, water-resistant, and aesthetically attractive plastic composites. These materials appear to be a product waiting for a market. In advanced construction applications where being lightweight and having high strength are important factors, these materials might provide a suitable answer.

\subsection{CONCLUSIONS}

During the course of this research project, tiles were prepared using polyester and acrylic resins. Three ash types were used: slag, fly ash, and three grades of cenospheres. The tiles produced varied in properties and have been described above in detail. It can be said in conclusion that:

- There is a high potential for the use of recycle plastic in the formulation of composite materials using CCBs as functional fillers.

- The use of CCBs in composites can result in materials considerably different from the parent materials and exhibiting properties of each of the starting materials.

- Strong and lightweight composites can be formed from plastic and cenospheres. Cenospheres, lightweight hollow ash particles in composites, can result in materials with high strength and a bulk density less than 1.0, making them lighter than water.

- A composite material incorporating fly ash can be prepared that is aesthetically pleasing, strong, and potentially wear-resistant.

- A composite can be prepared from slag and plastic that has skid resistance. The antislip properties of this composite might make an excellent safety product for applications where slippery conditions are likely.

- The adhesion of cement-based grout has high potential and should be evaluated.

- Up to nearly $80 \%$ replacement of plastic by weight can be achieved using fly ash or slag.

- With cenospheres and other functional fillers, up to $80 \%$ of plastic can be replaced with functional filler. Tiles were prepared with $20 \%$ plastic $-80 \%$ ash by volume. 